\title{
Immigrant faceism: documentation statuses evoke racialized mental representations
}

\author{
Joel E. Martinez ${ }^{1,2}$, DongWon $\mathrm{Oh}^{3}$, Alexander Todorov ${ }^{4}$ \\ ${ }^{1}$ Department of Psychology, Princeton University, Princeton, NJ, USA \\ ${ }^{2}$ Princeton School of Public and International Affairs, Princeton University, Princeton, NJ, UA \\ ${ }^{3}$ Department of Psychology, New York University, New York City, NY, USA \\ ${ }^{4}$ Booth School of Business, The University of Chicago, Chicago, IL, USA
}

Note: this manuscript has not been peer reviewed. 


\begin{abstract}
Politicized U.S. immigration discourse has spurred interest in characterizing who illegalized immigrants are or perceived to be. What are the associated visual representations of migrant illegality? Across two studies with undergraduate and online samples $(\mathrm{N}=686)$, we used facebased reverse correlation and spatial arrangement to capture representations of illegalized immigrant men and their differentiation from U.S. citizen or documented immigrant representations. Documentation statuses were differentially racialized. Immigrant representations were dark-skinned and classified as non-white, while citizen representations were light-skinned, evaluated positively, and classified as white. Legality further differentiated immigrant representations: documentation conjured positive representations, illegality conjured threatening representations. In a similarity task, participants used faces' pixel luminance (e.g., skin color) and perceived American-ness to sort unlabeled faces by documentation status, confirming their representational distinctions. Illegalized immigrants were uniquely racialized as dark-skinned unAmerican threats, highlighting the continued impact of U.S. imperial projects and colorism in shaping representations of migrant illegality.
\end{abstract}

Keywords: Immigration, Illegalization, Racialization, Face Representation, Reverse Correlation 


\section{Introduction}

A principal way in which the United States has managed immigration is through the legislation of citizenship and its exclusions. Its imperial relations to other countries created an extractive demand for foreign labor while internal policies restricted access to citizenship and formal inclusion. This dynamic resulted in the construction of deportable and illegalized immigrants (N. P. De Genova, 2002; Golash-Boza, 2015; Ngai, 2004). The history of migrant illegality is thus constituted by a combination of nativist and capitalist motives, resulting in contradictory immigration policies (Chauvin \& Garcés-Mascareñas, 2012, 2014). However, a common emergent theme within these policies and resulting political discourse is one of immigrants as threats (Chavez, 2013; Santa Ana, 1997), particularly illegalized immigrants (Ackerman, 2013; Brown, 2013; Inda, 2006; Warner, 2005). These threat frames spurred the development of technologies for better controlling and expelling illegalized immigrants (Inda, 2006; Provine \& Doty, 2011; Zatz \& Rodriguez, 2015) and of counter-actions in defense of immigrants (Costanza-Chock, 2014; Martinez et al., 2017). This dynamic history, coupled with the presence of hostility and contestation, has likely resulted in specific mental representations of illegalized immigrants. This project therefore aims to characterize who is mentally conjured when thinking about illegalized immigrants and how migrant illegality is psychologically encoded.

Facing illegality

Mental representations can be consequential. Beliefs about who the typical beneficiary of a policy is influences support for social policies (Brown-Iannuzzi et al., 2017; Gilens, 1996; Lord et al., 1994). In the case of immigration, policy preferences have been linked to the internal organization of "immigrants" as a mental construct, which determines the type of immigrant that 
becomes salient (Blinder, 2015; Martinez et al., 2021). This representational influence on social judgment becomes particularly troubling when linked to visual appearances (Stolier et al., 2020). For illegalized immigrants, visibility is a major concern and visual appearances are critical to the operation of surveillance environments in which they manage detectability (Asad, 2020; Garcia, 2019). Therefore, characterizing the upstream mental representations that impose specific meanings on others' appearances is vital for understanding how migrant illegality becomes socially reified.

We focus on the face as an understudied but potentially diagnostic visual feature in ascriptions of illegality. People extract assumptions about social category membership and character from even brief exposure to others' faces (Dobs et al., 2019; Willis \& Todorov, 2006) and these inferences can have persistent and damaging interpersonal consequences (Jaeger et al., 2020; Todorov, 2017; Todorov et al., 2015). Here, we use face-based reverse correlation to measure mental representations of what illegalized immigrants are thought to look like (Brinkman et al., 2017; Dotsch \& Todorov, 2012). This technique can approximate mental representations by repeatedly superimposing random noise over a face image, thus distorting its features, and having people choose which of the noisy images look like a cued target. The resulting images can reveal facial cues and dimensions relevant to the visualization of illegality.

\section{Potential dimensions of illegality representations}

The historical development of illegality suggests its representative visual features should be associated with perceptions of nationality and race (Sáenz \& Manges Douglas, 2015; Sanchez \& Romero, 2010). The Johnson-Reed Immigration Act of 1924 was the first to designate nationality quotas, which differentially restricted movement from countries on the Eastern Hemisphere (in favor of Northwestern European countries) while solidifying racist hierarchies. 
As Ngai states, "At one level, the new immigration law differentiated Europeans according to nationality and ranked them in a hierarchy of desirability. At another level, the law constructed a white American race, in which persons of European descent shared a common whiteness distinct from those deemed to not be white" (Ngai, 2004, p. 24). The Immigration Act of 1965 then removed the previous quotas but designated limits on visas from both hemispheres, which restricted movement from countries in the Western Hemisphere for the first time. The combination of numerical restrictions and U.S. agricultural labor demands increased “unauthorized” entries from Mexico (N. De Genova, 2004; Inda, 2006).

One prediction that follows is that people mentally represent illegalized immigrants as "non-white", "Latinx", or maybe more specifically, as Mexican. This prediction is borne out in contemporary sociological (Flores \& Schachter, 2018) and psychological research (Lee \& Fiske, 2006; Pérez, 2010) on perceived associations between nationality and illegality. It is also borne out in immigration legislation. For example, the ruling of United States v. Brigoni-Ponce (1975) allowed border agents to use "Mexican appearance" as one (though not only) relevant cue when identifying drivers as illegalized immigrants (Garcia, 2019). However, populations marked by illegality are dynamic due to shifting migration patterns and foreign policies. The recent rise in illegalized immigrants from Asian and Central American countries and decline from Mexico could have modified the Mexican-illegal association (Passel \& Cohn, 2019).

An additional complication arises in that thinking of or encountering a Mexican or person from any nationality can involve a wide range of facial appearances. This is because national and race categories group together a collection of visually heterogeneous people and do not have a factual basis in biology, thus cannot be truly read from a face (Fields \& Fields, 2012; Todorov, 2017). Categorical associations alone cannot predict when someone might be visually identified 
as Mexican and further as illegal- this requires visual inferences that are read into the face ${ }^{1}$. It is therefore important to interrogate perceivers' visual preconceptions of these categories. One likely cue is phenotypicality (Maddox, 2004; Nicolas \& Skinner, 2017): the restricted range of skin pigmentation and facial features that are assumed to be representative of certain races or nationalities. The more ones' facial appearance matches a category's presumed prototypical phenotype, the more likely they will experience the consequences that come from being identified as that category (Maddox \& Perry, 2018). A focus on phenotypic face representations can inform how individuals may be (mis)identified as illegal regardless of their actual citizenship status.

Other likely dimensions are evaluations of threat, ability, or morality, which can be encoded into visual representations as affective facial expressions (Oosterhof \& Todorov, 2008). Illegalized immigrants are often painted by conflicting portrayals in public discourse. The ongoing political framing of illegalized immigrants as a criminal threat (Alamillo et al., 2019) has been met with forms of resistance like highlighting immigrant achievement (Martinez et al., 2017). Illegalized immigrants have made great strides in public and academic arenas by speaking back against their (mis)representation (Abrego \& Negrón-Gonzales, 2020; Costanza-Chock, 2014). One important component of their activism is a strategic focus on controlling media portrayals through various public narratives. Examples include curating images of being deserving model immigrants who embody normative American values, adopting humanitarian frames that avoid internal marginalization (e.g., "no human being is illegal"), or challenging the presumed validity of citizenship and immigration enforcement regimes (Lauby, 2016; Pon, 2018;

\footnotetext{
1 There are other important cues such as language, geography, material surroundings, social networks, and much more that are incorporated into this kind of judgment. We focus on faces as one of many potential features.
} 
Swerts \& Nicholls, 2020; Yukich, 2013). The common thread across strategies is a push for humanization, which has led to some policy successes ${ }^{2}$. These narrative interventions and policy victories may have blunted public understandings of illegalized immigrants as a threat, a shift which may be reflected in mental representations (e.g., Martinez et al., 2021).

\section{Current Project}

The current project investigates how illegalized immigrants are mentally represented. By using face-based reverse correlation, we are assuming that representations of migrant illegality can be meaningfully captured and gleaned from face representations. Two studies tested this assumption while providing insights into representational content. Study 1 visualized representations of illegalized immigrants, compared them to representations of other documentation statuses (i.e., documented immigrants, U.S. citizens), and investigated the ethnoracial and evaluative cues elicited from both face representations. Following standard procedure, the average classification images of each documentation status were rated. However, considering methodological concerns that ratings of the average classification image can produce false positives (Cone et al., 2020), the individual classification images were also rated. The faces were rated on four traits fundamental to social cognition and perceptions of immigrants and citizens: dangerous (Chavez, 2013), trustworthy (Oosterhof \& Todorov, 2008), competent (Lee \& Fiske, 2006), and American (Devos \& Banaji, 2005).

As an additional test that illegality evokes a distinct mental representation, Study 2 investigated whether participants would spontaneously sort the unlabeled faces from Study 1 by

\footnotetext{
2 Successes include several executive actions: Deferred Action for Childhood Arrivals (DACA) and the currently defunct Deferred Action for Parents of Americans (DAPA), which provided many the right to work and protection from deportation. The Development, Relief, and Education for Alien Minors (DREAM) Act, a more comprehensive reform bill fueled by organized activism, was almost passed in 2010 (American Immigration Council, 2020).
} 
documentation status if asked to judge visual similarity. The resulting sorting patterns were then used to identify the relative contributions of various facial cues to sorting performance. To the extent that reverse correlation can capture meaningful representations of documentation statuses, we expect both studies to show that trait ratings and similarity judgments by naïve samples differentiate face representations by documentation status.

\section{Study 1 - Mental representations of documentation statuses}

Since migrant illegality is a mechanism of exclusion from citizenship, its representation can best be contextualized through relative comparisons to representations of citizens, but also to documented (i.e., legal) immigrants. The latter juxtaposition is frequently made by policies demarcating lawful beneficiaries of public goods and by immigrant- or ethnic-based activism hoping to better their positions by distancing themselves from illegality (Brown, 2013; Waters \& Kasinitz, 2015). The comparison between citizen and immigrant representations identifies features specific to representing immigrants, the comparison between documented and illegalized immigrant identifies features specific to representing illegality ${ }^{3}$.

\section{Methods}

Following the typical two-stage reverse correlation task design, an image generating task was followed by image rating tasks with naïve samples. All the data, analysis scripts, and preregistration are available on the Open Science Framework archive:

3 We acknowledge that the legal/illegal distinction is technically blurry as documented immigrants also have a precarious legal status through ever-stringent immigration enforcement and illegalized immigrants can have liminal legality such as informal integration into local institutions (Chauvin \& Garcés-Mascareñas, 2014; Menjívar \& Kanstroom, 2014); however blurry institutional realities may not necessarily translate to blurry social distinctions (Brubaker et al., 2004). 
https://osf.io/jzp3e/?view_only=68d3a6f348934be09a5412a1caab711d. The project was approved by the Princeton University IRB \#7301.

Image generating task

Participants

Princeton University students were recruited for course credit $(\mathrm{N}=181)$. Data were collected between November 2017 and May 2018. For details of our exclusion criteria please see Supplementary Note S1. The final sample included 150 students, 50 in each condition $\left(\mathrm{M}_{\mathrm{age}}=19.7, \mathrm{SD}_{\mathrm{age}}=1.81\right)$. The gender distribution was 57 men and 93 women. The racial distribution was 79 white, 48 Asian, 5 black, 7 Latinx/a/o, 8 Multiracial, and 3 whose race was not listed. Lastly, on a scale of never (1) to all the time (7), participants reported on average some level of contact with immigrants in their daily life $(\mathrm{M}=4.57, \mathrm{SD}=1.93)$. Less than 5 students reported never having contact. There were no significant sample distribution differences between conditions on gender, self-reported immigrant contact, and age (ps>.20).

While we acknowledge the limitations associated with undergraduate samples, we note that in this case Princeton University provides an interesting test. In general, there are few illegalized immigrants in higher education (around $2 \%$ of students in higher education), which means most universities have a small number of illegalized immigrant students who experience varied levels of institutional support and visibility (New American Economy, 2020). However, Princeton University experienced DACA-related ${ }^{4}$ activism during data collection for this study, including narrative sharing by students with DACA in local news and a university complaint filed against the U.S. government's attempt to end the DACA program (Princeton University Office of Communications, 2020; Wenner, 2018). This Princeton sample was therefore collected

\footnotetext{
${ }_{4}$ See footnote 2 .
} 
in a context where the aforementioned discourses of immigrant belonging, achievement, and threat were salient on campus.

\section{Procedure}

After completing consent forms, participants were led into a room which contained a single computer and chair. The reverse correlation task began with instructions about the content of the task and how to complete it. Participants were asked to visualize one of three different documentation statuses (i.e., undocumented immigrants, documented immigrants, or U.S. citizens). To minimize definitional error, we provided definitions for each documentation status: "Undocumented immigrants live in the U.S. without legal immigrant status", "Documented immigrants live in the U.S. with legal immigrant status", "Citizens are born in the U.S.". While citizens can be naturalized immigrants, we wanted participants to visualize what they perceive to be native-born citizens. Participants were instructed that they would be presented with two images and to press the " 0 " key if the face on the right looked more like the visualized target and the "1" key if the left face looked like the target. Both images were displayed as $9 \mathrm{~cm} \mathrm{x} 9 \mathrm{~cm}$. Each trial displayed the two faces side by side on the center of the screen with the sentence “Which looks more like a [condition target]?” underneath. Participants completed 770 self-paced trials. After each response there was a 1 second fixation cross before the next trial. Since this was an in-lab sample, more trials can improve the quality of the resulting images (Brinkman et al., 2019). Lastly, participants provided demographic information.

\section{Stimulus generation}

The base face was a morph of all the male faces from the London Face Database (DeBruine \& Jones, 2017). We focused on male faces to reflect the gendered nature of immigration deportations at the time of data collection: about $85 \%$ to $90 \%$ of deportations have 
been Latino men (Golash-Boza \& Hondagneu-Sotelo, 2013). A total of 770 pairs of stimuli were created by repeatedly superimposing random sinusoid noise over the base face using the rcicr package (Dotsch, 2017).

\section{Classification image generation}

Individual and average face classification images were computed using the rcicr package. The general analytic procedure includes averaging the noise patterns of the selected images in the reverse correlation task per participant. This average noise pattern is superimposed on the base face to create participant-level faces. The average noise pattern of all selected images across participants is superimposed on the base face to create the sample-average face.

\section{Image rating task}

\section{Participants}

Trait inferences about the classification images were derived from ratings by an independent group of naïve participants. Ratings were collected from various samples on Amazon Mechanical Turk. Specifically, we asked participants about how American, competent, dangerous, and trustworthy the person in the resulting reverse-correlated images appeared. We conducted a simulated mixed-effect regression power analysis that quantified power for a main effect of documentation status on ratings using the simr package in R (Green \& Macleod, 2016). Given a hypothesized effect size of $f=.77$ based on previous studies (Kunst et al., 2017), we tested the impact of increasing the number of participants from 20 to 200 on power. Our simulation estimated that as low as 20 participants would provide $99.90 \%$ power. However, we increased the number to 40 per rating sample to account for inaccuracies in simulation assumptions and likely exclusions from unreliable data in online samples (see Supplementary Note S1). We consider unreliability as data from participants that exhibited a test-retest 
reliability of zero or less (see Procedure for details). The following describes the final samples after exclusions. The average faces were rated in December 2018 on Americanness $(\mathrm{N}=40$, $\mathrm{M}_{\mathrm{age}}=40.7, \mathrm{SD}_{\mathrm{age}}=13.2,21$ Men, 19 Women $)$, competence $\left(\mathrm{N}=40, \mathrm{M}_{\mathrm{age}}=36.1, \mathrm{SD}_{\mathrm{age}}=10.6,20\right.$ Men, 20 Women), dangerousness $\left(\mathrm{N}=40, \mathrm{M}_{\mathrm{age}}=37.4, \mathrm{SD}_{\mathrm{age}}=12.1,23\right.$ Men, 17 Women $)$, trustworthiness $\left(\mathrm{N}=40, \mathrm{M}_{\mathrm{age}}=39.3, \mathrm{SD}_{\mathrm{age}}=11.6,24 \mathrm{Men}, 16\right.$ Women), and ethnoracial category $\left(\mathrm{N}=40, \mathrm{M}_{\mathrm{age}}=36.2, \mathrm{SD}_{\mathrm{age}}=9.62,26 \mathrm{Men}, 14\right.$ Women $)$.

To mitigate potential inflations of Type 1 error by presenting all the visual heterogeneity contained within the full set of individual faces in each condition (Cone et al., 2020), the individual faces were rated in November 2018 on Americanness $\left(\mathrm{N}=35, \mathrm{M}_{\mathrm{age}}=38.3, \mathrm{SD}_{\mathrm{age}}=14\right.$, 15 Men, 20 Women $)$, competence $\left(\mathrm{N}=30, \mathrm{M}_{\mathrm{age}}=38.4, \mathrm{SD}_{\mathrm{age}}=11.2,16\right.$ Men, 14 Women), dangerousness $\left(\mathrm{N}=37, \mathrm{M}_{\mathrm{age}}=39.1, \mathrm{SD}_{\mathrm{age}}=11.4,19\right.$ Men, 18 Women $)$, and trustworthiness $(\mathrm{N}=$ 33, $\mathrm{M}_{\mathrm{age}}=36.7, \mathrm{SD}_{\mathrm{age}}=13.1,22 \mathrm{Men}, 10$ Women, 1 Non-binary). We collected many individual difference measures to better characterize the raters; however, they were not analyzed here. See Supplementary Tables S1 and $\mathbf{S 2}$ for descriptive statistics of all participant measures.

\section{Procedure}

After providing consent, participants were shown a series of faces one by one and evaluated them on a scale of 1 (not at all) to 9 (extremely) on one of four traits: American, dangerous, competent, or trustworthy. Each face image was presented at 300 pixels x 300 pixels. All trials were self-paced and there was a $250 \mathrm{~ms}$ delay before the next trial. For the average classification faces, this included the three faces from each condition in randomized order. For the individual classification faces, this included the 150 faces (50 from each condition) in randomized order. We repeated a random subset of 45 faces (15 from each condition) to assess test-retest reliability (see Supplementary Table S1 and S2). For each participant, test-retest 
reliability was defined as a correlation between repeated responses to the same stimuli. During each trial, the face was shown in the center of the screen with the following question underneath "How [trait] is this person?" followed by the scale. For the race classification task, only the three average faces were shown as it would be a highly demanding task with a full stimulus set. Eight ethnoracial category sliders were shown below each face, ranging from 0 to 100 . Participants recorded how likely each face was a member of each ethnoracial category (black, white, American Indian or Native American, East Asian, Hawaiian or Pacific Islander, Latinx/a/o or Hispanic, South Asian or Indian, Middle Eastern). The slider values were independent of each other (e.g., each slider could be set to 100). All rating tasks ended with demographic and participant measures.

Analyses

Trait and race ratings for the average faces ( 3 faces rated once) were analyzed using maximal mixed models (Barr et al., 2013) with maximum likelihood estimation in the lme4 package in R (Bates et al., 2015; R Core Team, 2015). Documentation status was a fixed effect and random intercepts were allowed to vary by participant. Trait ratings for the individual faces (150 faces, 50 repeated twice) were also analyzed using mixed models where documentation status was a fixed effect. Random intercepts and random slopes for documentation status were allowed to vary by participant, and random intercepts were allowed to vary by stimuli and by the interaction between participants and stimuli to account for the repeated measures. To help these complex models converge, we used an iterative optimizer algorithm (bound optimization by quadratic approximation; bobyqa) with the maximum number of iterations set to 500,000 . Estimated marginal means, effect sizes $(d)$, and confidence intervals for both were calculated from the models using the emmeans package (Lenth, 2020). Degrees of freedom were estimated 
using the Satterthwaite approximation. Effect sizes were calculated from the mixed models to best approximate Cohen's $d$ by using the sum of the all variance components and residual variance as the population SD (Westfall, 2016). Multiple comparisons were corrected for false discovery rate.

\section{Results}

\section{Ethnoracial classifications}

The average classification images show highly distinct visual representations for different documentation statuses (Figure 1A). These visual distinctions occurred along low-level features (e.g., skin color, facial features), which influenced their perceived ethnoracial memberships (Figure 1B). Every ethnoracial category $(\mathrm{N}=8)$ exhibited a significant main effect of documentation status (range of $F s(2,78)=[5.75,1043.5]$, range of $p s=[<.0001, .005])$. The average citizen face was perceived as most likely to be white compared to the average documented immigrant $(b=86.1 \mathrm{CI}[80.7,91.5], d=8.43 \mathrm{CI}[7.3,9.6], \mathrm{t}(78)=39.01, \mathrm{p}<.0001)$ and undocumented immigrant face $(b=88.5 \mathrm{CI}[83.1,93.9], d=8.66 \mathrm{CI}[7.5,9.9], \mathrm{t}(78)=40.1, \mathrm{p}<.0001)$. Conversely, both immigrant faces were perceived as more likely to be from all the other ethnoracial categories compared to the citizen face. The largest difference between the undocumented immigrant and the citizen face occurred for the black category $(d=2.09 \mathrm{CI}[1.60$, 2.60]), the smallest was the American Indian/Native American category ( $d=0.43 \mathrm{CI}[.06, .81])$. The largest difference between the documented immigrant and citizen face occurred for the black category $(d=1.51 \mathrm{CI}[1.04,1.97])$, the smallest was the Middle Eastern category $(d=0.35 \mathrm{CI}[.03$, .73]). The only ethnoracial category in which the documented and undocumented immigrant

faces were rated significantly differently was the black category. The undocumented immigrant face was perceived as more likely to be black ( $b=-15.5 \mathrm{CI}[-29.3,-1.70], d=-.58 \mathrm{CI}[-1.01,-.16]$, 
$\mathrm{t}(78)=-2.75, \mathrm{p}=.007)$. Undocumented-black was also the only rating to exceed $50 \%$ likelihood within both the documented and undocumented ratings $(\mathrm{M}=57.6 \mathrm{CI}[49.2,65.9])$.

To summarize, the citizen face was perceived as mostly white, while the two immigrant faces were perceived as anything-but-white. The undocumented immigrant face was also perceived most likely as black, compared to the other two faces.

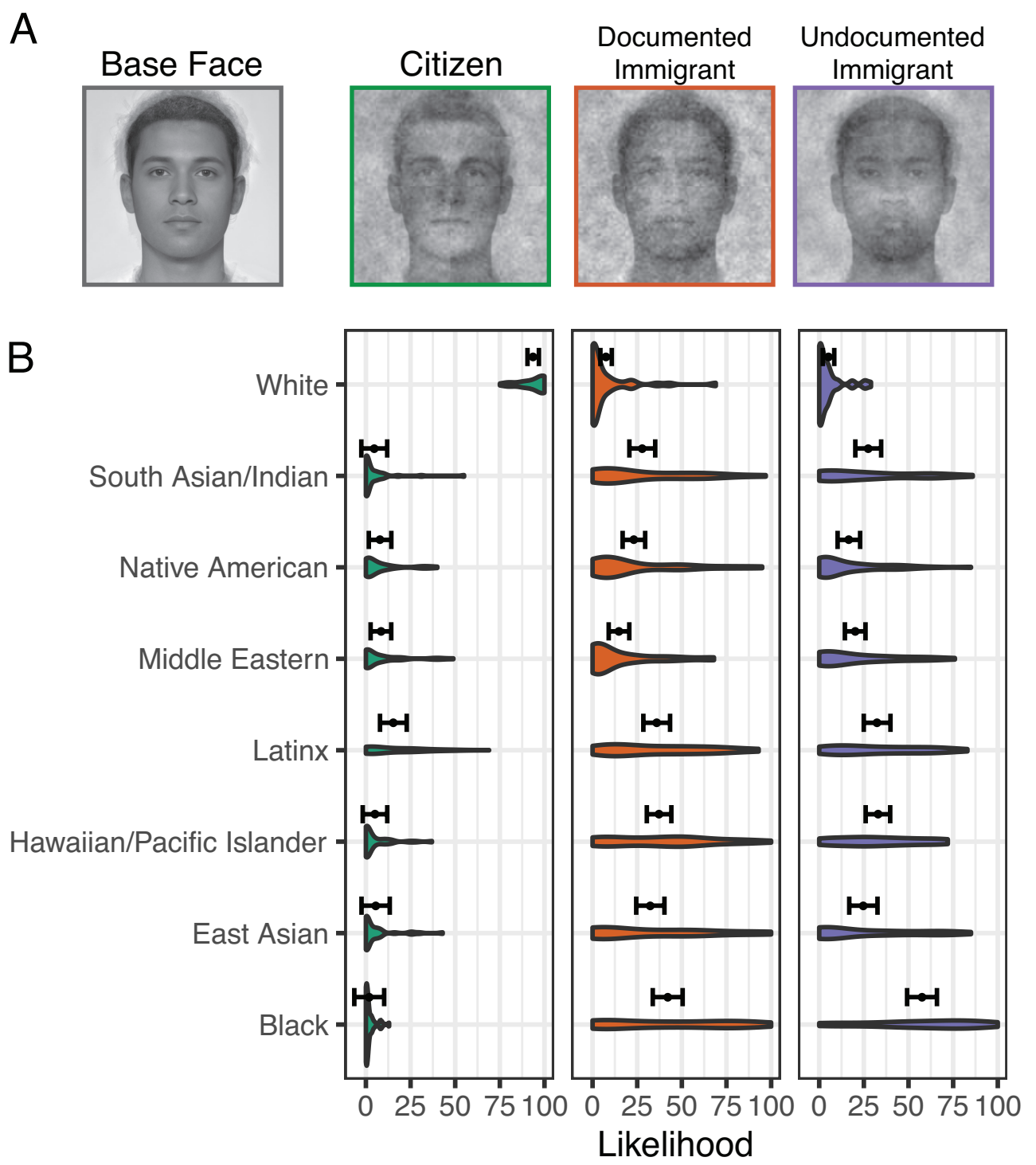

Figure 1. Average classification images and race classifications. A) The base face used in the reverse correlation task, presented alongside with the average classification faces in the citizen (green), documented immigrant (orange), and undocumented immigrant (purple) condition. B) Ethnoracial classifications of the average faces. The $\mathrm{x}$-axis is the perceived likelihood that each face was a member of the ethnoracial categories on the y-axis. The violin graphics display the 
density of the data points. The points and error bars above the violins represent the means and $95 \%$ confidence intervals.

\section{Trait ratings}

Average classification image ratings. Documentation status significantly predicted American $(F(2,80)=29.6, p<.0001)$, competent $(F(2,80)=4.1, p=.021)$, dangerous $(F(2,80)=36.9$, $p<.0001)$, and trustworthy ratings $(F(2,80)=25.1, p<.0001)$ (Figure 2A). The undocumented immigrant face was on average rated as less American $(b=-2.88 \mathrm{CI}[-3.88,-1.86], d=-1.22 \mathrm{CI}[-$ $1.61,-.84], t(80)=-6.94, p<.0001)$, competent $(b=-1.0 \mathrm{CI}[-1.86,-.13], d=-.58 \mathrm{CI}[-.99,-.17]$, $t(80)=-2.84, p=.017)$, trustworthy $(b=-1.82 \mathrm{CI}[-2.58,-1.07], d=-1.03 \mathrm{CI}[-1.4,-.66], t(80)=-5.92$, $p<.0001)$, and more dangerous than the citizen face $(b=2.52 \mathrm{CI}[1.72,3.33], d=1.42 \mathrm{CI}[1.0$, 1.83], $t(80)=7.68, p<.0001)$. The documented immigrant face was only significantly rated as less American than the citizen face $(b=-2.65 \mathrm{CI}[-3.64,-1.61], d=-1.12 \mathrm{CI}[-1.5,-.74], t(80)=-$ 6.34, $p<.0001)$. The undocumented immigrant and documented immigrant faces were only significantly different in their perceived dangerousness $(b=-2.35 \mathrm{CI}[-3.15,-1.55], d=-1.32 \mathrm{CI}[-$ $1.73,-.92], t(80)=-7.16, p<.0001)$ and trustworthiness $(b=1.95 \mathrm{CI}[1.19,2.70], d=1.10 \mathrm{CI}[.73$, 1.47], $t(80)=6.33, p<.0001)$.

Individual classification image ratings. Documentation status remained a significant predictor of American $(F(2,101.8)=14.99, p<.0001)$, competent $(F(2,82.3)=10.56, p<.0001)$, dangerous $(F(2,148.8)=13.46, p<.0001)$, and trustworthy $(F(2,107.9)=5.63, p=.005)$ ratings

(Figure 2B). The undocumented immigrant faces were on average rated as less American $(b=-$ $1.02 \mathrm{CI}[-1.49,-.55], d=-.46 \mathrm{CI}[-.64,-.28], t(81.3)=-5.34, p<.0001)$, competent $(b=-.62 \mathrm{CI}[-.96,-$ $.28], d=-.32 \mathrm{CI}[-.47,-.18], t(59.5)=-4.47, p=.0001)$, trustworthy $(b=-.56 \mathrm{CI}[-.98,-.15], d=-.28$ $\mathrm{CI}[-.45, .11], t(48.8)=--3.31, p=.004)$, and more dangerous than the citizen faces $(b=.75 \mathrm{CI}[.38$, $1.12], d=0.37 \mathrm{CI}[.22, .51], t(148.3)=4.91, p<.0001)$. 
Similarly, the undocumented immigrant faces were rated as less American $(b=-.35 \mathrm{CI}[-$ $.69,0], d=-.16 \mathrm{CI}[-.64,-.28], t(135.9)=-2.40, p=.018)$, competent $(b=-.29 \mathrm{CI}[-.52,-.06], d=-.15$ $\mathrm{CI}[-.25,-.05], t(142.6)=-3.09, p=.004)$, trustworthy $(b=-.29 \mathrm{CI}[-.59, .02], d=-.14 \mathrm{CI}[-.27,-.02]$, $t(148.4)=-2.25, p=.039)$, and more dangerous than the documented immigrant faces $(b=.55$ $\mathrm{CI}[.22, .88], d=0.27 \mathrm{CI}[.13, .39], t(154.5)=4.02, p=.0001)$. The documented immigrant faces were only significantly rated as less American ( $b=-.67 \mathrm{CI}[-1.04,-.31], d=-.30 \mathrm{CI}[-.44,-.17]$, $t(127.5)=-4.46, p<.0001)$ and competent than the citizen faces $(b=-.33 \mathrm{CI}[-.63,-.02], d=-.17$ $\mathrm{CI}[-.30,-.04], t(70.9)=-2.62, p=.011)$.

To summarize, the general patterns of ratings suggest that the undocumented immigrant face was evaluated worse on all the traits compared to the citizen face. The documented and undocumented faces were rated similarly on evaluations of Americanness and ethnoracial categories, but differently in social evaluations. The documented face was instead closer to the citizen face on social evaluations. This suggests that affective expressions marked an illegal/legal distinction within immigrants more so than skin tone or phenotype. 

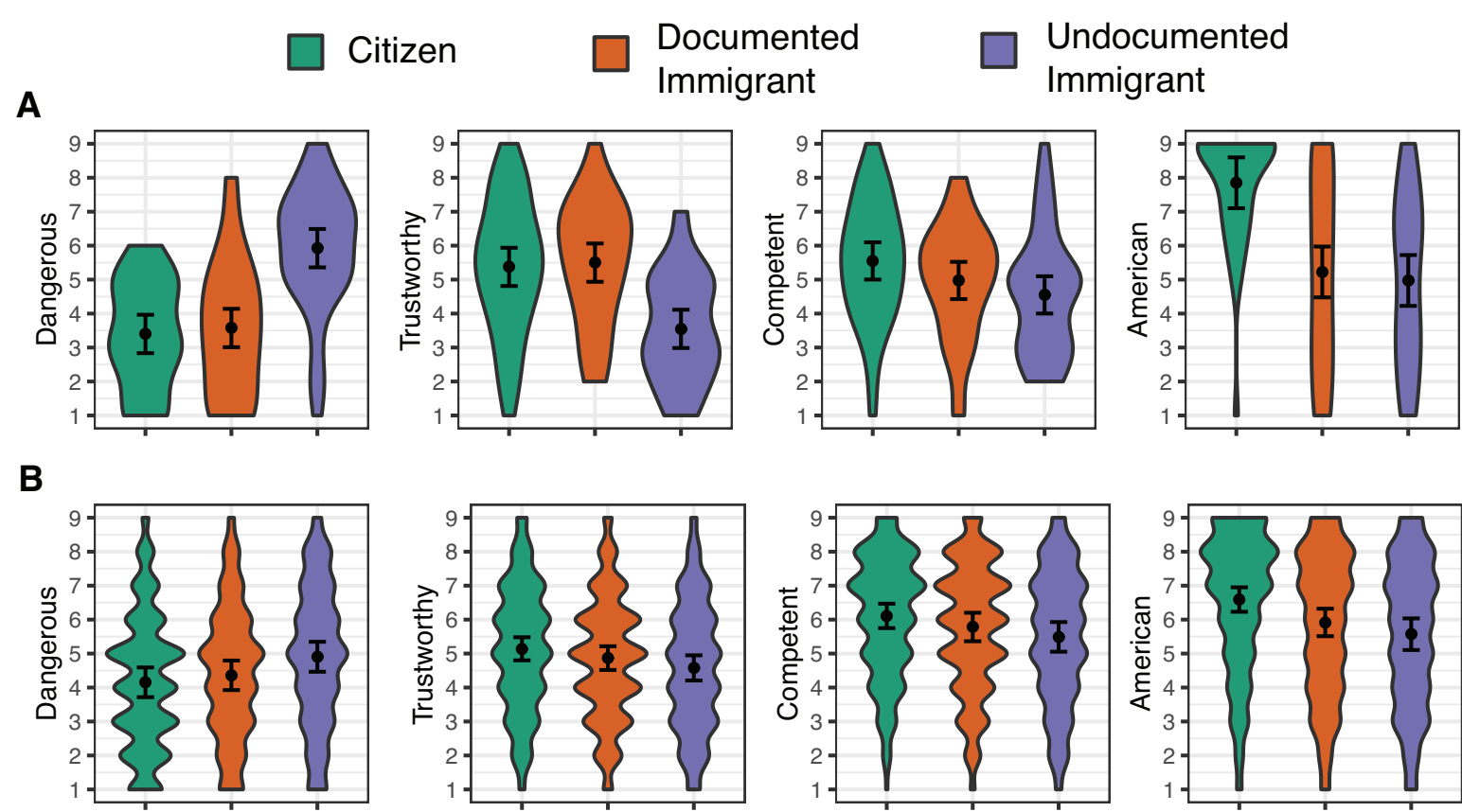

Figure 2. Trait ratings of average and individual classification images. A) Ratings of average classification face for U.S. citizen (green), documented immigrant (orange), and undocumented immigrant conditions (purple). B) Ratings of the individual classification images. The violin shapes reflect the density of the rating data much like a sideways density plot. The error bars represent $95 \%$ confidence intervals.

\section{Replication in a separate sample}

Although the Princeton sample provides an interesting contextual sample, a potential critique is the lack of generalizability of the representation of undocumented immigrants. To address this issue, we compared the results from the current project with results from a subsequent study in November 2019 using an online sample localized to two Mexico-bordering states - a geographically and socio-politically different region from New Jersey. We found similar outcomes suggesting the average representation of undocumented immigrants from

Figure 1A replicated a year later in a broader U.S. sample (Supplementary Figure S1).

\section{Discussion}

The goal of this study was to visually characterize mental representations of illegalized immigrants. We investigated what kind of cues are unique to representing illegality through 
comparisons with U.S. citizen and documented immigrant representations. The results show that representations of documentation statuses are differentially racialized. Replicating research suggesting a widespread implicit American-white associations (Devos \& Banaji, 2005), we find that the immigrant representations were perceived as likely to belong to every ethnoracial category except white, while the U.S. citizen representation was perceived as likely to only be white. The illegalized immigrant representation was more likely to be perceived as belonging to the black category than to any other category and more than the other documentation statuses. In line with theorizing on the socially reified relationship between phenotypic blackness and perceived badness or threat (Alter et al., 2016; Eberhardt et al., 2004; Maddox \& Perry, 2018), the illegalized immigrant representations also received worse evaluations than the citizen and documented representations as less trustworthy and competent and more dangerous. These patterns held in the ratings of the individual faces suggesting that, despite heterogeneity in the individual faces, raters perceived some common facial cues that differentiated documentation status representations.

Comparisons with the documented immigrant representations revealed nuances underlying the legal/illegal distinction: the documented immigrant was represented as both distinct from and similar to illegalized immigrants. They were similar on evaluations of ethnoracial classification or Americanness, but they differed on moral evaluations - documented immigrants were instead evaluated as positively as U.S. citizens. While research suggests that immigrant acculturation physically "whitens" immigrant representations (Kunst et al., 2017), our results suggest legal status alone does not, but it does produce positive representations.

\section{Study 2 - Sorting unlabeled representations of documentation statuses}


As an additional test that illegality has a unique mental representation, this study sought to understand how distinct the representational boundaries between documentation statuses are. In Study 1, the ratings from participants naïve to the documentation status conditions of the faces suggested that skin color (i.e., pixel luminance) and affective expression operate as cues that distinguish between documentation status representations. However, one could argue that trait rating tasks direct raters' attention to specific cues related to the documentation status and the trait. For instance, dangerous evaluations could direct raters' to explicitly search for frowns or darker skin. If asked to instead assess holistic visual similarity, how well could naïve participants spontaneously sort the faces by documentations status? This would provide converging evidence that there are salient features visualized into representations of different documentation statuses that others spontaneously identify. This study also sought to identify which cues are spontaneously used to sort the faces by similarity - those related to certain social evaluations and/or to low-level features related to pixel luminance values (e.g., skin color, high contrast features).

Participants spatially sorted the unlabeled faces by similarity (i.e., spatial arrangement method; Koch et al., 2020). By computing the pairwise distances between the faces in the final sorting pattern (Figure 3), one can estimate how (dis)similar faces of the same documentation status are perceived to be. 

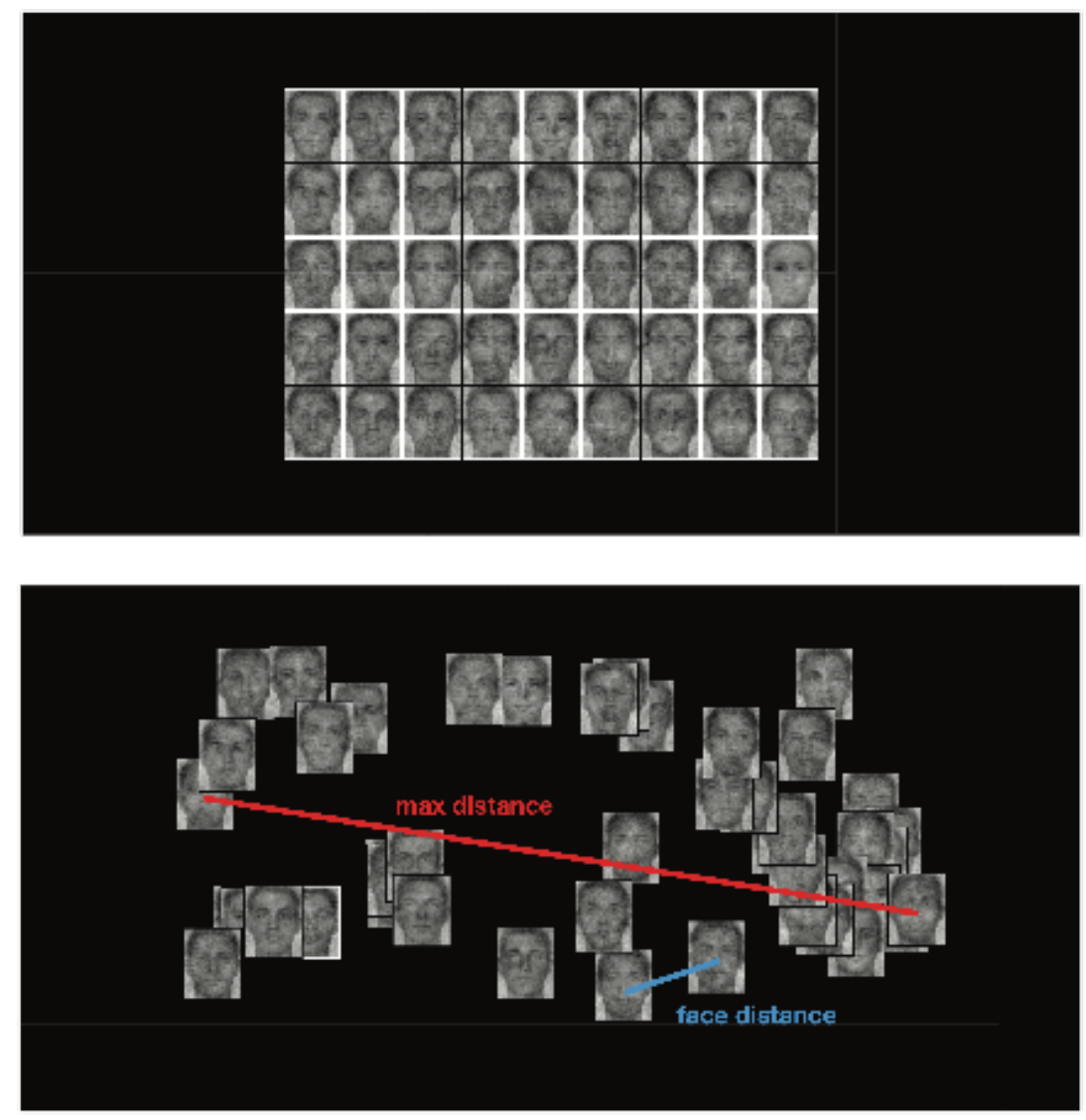

Figure 3. Spatial Arrangement Task. The top panel is an example screen of the beginning of the task. Faces are arranged in a rectangular format on random locations. The bottom panel reflects an example of what the screen might look like after a participant sorted the faces by similarity. The max distance is the dissimilarity between the two furthest faces on screen (red). The face distance is the dissimilarity between each pair of individual faces (blue).

If participants are successful at sorting the faces, face representations from the same documentation status should be placed near each other and apart from faces from the other documentation statuses. Then, one way to identify the cues that strongly contributed to those decisions is to relate the visual similarity between two faces (i.e., their spatial distance) to the similarity between the same two faces on other measures: trait ratings and pixel luminance values. If a low-level cue, like skin color, facilitates the spontaneous sorting of documentation status, then the pixel similarity between two faces should correlate with their spatial distance. If 
facilitation instead occurs from evaluative inferences made about the faces, then the trait similarity between two faces should correlate with their spatial distance. Note that these two types of cues are not mutually exclusive, and it is likely that both types of facial cues give rise to face categorization along documentation status, and we can assess their relative contributions.

\section{Methods}

\section{Participants}

The sample consisted of 201 participants from Amazon Mechanical Turk $\left(\mathrm{M}_{\mathrm{age}}=39\right.$, $\mathrm{SD}_{\text {age }}=11.4,103$ Women, 96 Men, 2 whose gender was not listed). See Supplementary Table $\mathbf{S 3}$ for the full descriptive demographics. Given the task design (see below for more details), we estimated that 200 participants would provide a large enough sample size to ensure that there would not be any empty face-pair cells (200 participants * 990 unique pairwise combinations from sorting 45 faces $=198,000 / 11,175$ unique pairs from a 150 face similarity matrix $=17.7$ participants per cell on average). The resulting average sample size per face pair was $18(\mathrm{SD}=4)$.

\section{Procedure}

After providing consent and reading the task instructions, participants were presented with a black screen that presented 45 faces in the center organized in a 9 row x 5 column grid (see Figure 3). Participants were instructed that their task was to spatially sort (via drag and drop) the faces by similarity according to the following guidelines: "use the entire screen, place more similar faces closer together, place more dissimilar faces further apart." Participants could not advance until they moved every face and were given a second chance to change their sorting decisions after clicking "continue" the first time. The 45 faces were chosen at random from the reverse-correlated faces generated in Study 1, consisting of 15 faces from each condition (U.S. citizen, documented immigrant, undocumented immigrant), and randomly placed on the grid. 
This was to make the sorting task tractable given that there were 150 faces in total. The randomization ensured that different participants sorted some of the same and some different pairs of faces from each condition with the goal that every pair of faces would be seen by a reasonable number of participants. Lastly, participants answered the same demographic and individual difference measures as in Study 1. Data were collected in November 2018.

\section{Measures}

We constructed six face $\mathrm{x}$ face similarity matrices: one for visual sorting similarity, one for pixel similarity, and four for trait similarities (Supplementary Figure S2).

Inter-face visual similarity. The main dependent measure was the spatial distance between each pair of faces. Since the task was presented on a variety of screen sizes (although we ensured that participants could not participate if their screen was smaller than $1370 \times 768$ pixels), we decided to create a normalized index of interface similarity. The distance between each pair of faces on the screen was considered their dissimilarity. To account for varied screen sizes, for each participant, we divided pair distances by the max distance between any two faces (see Figure 3). We subtracted these distances from 1 to transform them into similarity scores that ranged from 0 (the max distance any two faces could be) to 1 (completely overlapping on screen). The outcome was a face $\mathrm{x}$ face similarity matrix for each participant. Since the instructions did not provide any strategies for how participants should sort (e.g., optimizing cluster boundaries by completely spatially separating face clusters vs. generally placing faces in different areas without attempting to clarify the boundaries), this procedure captures a noisy or conservative measure of category sorting.

Inter-face pixel similarity. The pixel similarity matrix was constructed by transforming the pixel luminance values from the noise pattern from each individual-level classification image 
into a vector, masking out the pixel space external to the contours of the face, and correlating pairs of pixel vectors.

Inter-face trait similarity. The trait matrices were constructed by taking the absolute difference of the average rating given to each face in a pair. The rating data from Study 1 (Figure 2B) were used as the input for these matrices.

Analyses

Similarity by documentation status. If sorting successfully captures the documentation statuses of the faces, faces within a category should be more similar than across categories. To test for this pattern, we combined each participant's similarity matrix while only taking the unique values (i.e., lower triangle). We ran a mixed model where each face pair's similarity was predicted by their documentation statuses (i.e., a categorical variable indicating the types of the combined pair of documentation statuses of faces, namely, $\mathrm{CC}=$ citizen-citizen pairs, $\mathrm{DD}=$ documented-documented pairs, $\mathrm{UU}=$ undocumented-undocumented pairs, and all crosscategory combinations: $\mathrm{CU}, \mathrm{CD}, \mathrm{DU})$. To account for the repeated pairs at the level of participants and faces, the random effects included random intercepts for participant and for the first face in the pair and separately for the second face in the pair. The model was optimized using bobyqa and allowed to iterate up to 500,000 times. Estimated marginal means and confidence intervals from the model were computed using the emmeans package. Multiple comparisons were corrected for false discovery rate and the degrees of freedom were estimated using the Satterthwaite approximation.

Relations between trait similarity, pixel similarity, and sorting similarity. To assess the relations between these different similarity matrices, we employed representational similarity analysis (Kriegeskorte et al., 2008). We computed raw pairwise Spearman correlations between 
the unique values in each matrix (i.e., lower triangles). However, there are likely relationships between all of the similarity matrices such that calculating the correlation between any two of them (e.g., trustworthiness and sorting similarity) will contain information about the other matrices. To account for this, we also computed partial correlations. By first removing any variance due to the other matrices not currently being correlated and then correlating the residuals, we can get a better measure of the direct relationships between any two matrices while controlling for the rest. Confidence intervals were obtained using the psych package (Revelle, 2018), see Supplementary Table S4.

\section{Results}

\section{Documentation status sorting similarity}

The face pairs' combined category label was a significant predictor of similarity scores $(F(5,413.1)=23.37, p<.0001)($ Figure 4A). Undocumented-undocumented face pairs were more similar than undocumented-citizen $(b=.06 \mathrm{CI}[.03, .08], \quad t(259)=7.33, p<.0001)$ and undocumented-documented pairs $(b=.02 \mathrm{CI}[.001, .04], t(189)=3.15, p=.004)$. Likewise, citizencitizen face pairs were more similar than citizen-undocumented $(b=.06 \mathrm{CI}[.03, .08], t(279)=$ 7.34, $p<.0001)$ and citizen-documented $(b=.03 \mathrm{CI}[.01, .05], t(230)=4.04, p=.0002)$ pairs. However, documented-documented face pairs were not significantly more similar than documented-citizen $(b=.009 \mathrm{CI}[-.02, .03], t(190)=1.41, p=.202)$ or documented-undocumented pairs $(b=.002$ CI-.02, .02], $t(186)=0.41, p=.734)$. Overall, these patterns suggest that citizen and undocumented face representations contained signals that facilitated sorting and that seemed to somewhat oppose each other (i.e., citizen-undocumented pairings exhibited the lowest average similarity scores), while documented faces tended to be perceived as similar to both citizen and undocumented faces- indicative of a category with visually mixed boundaries. 

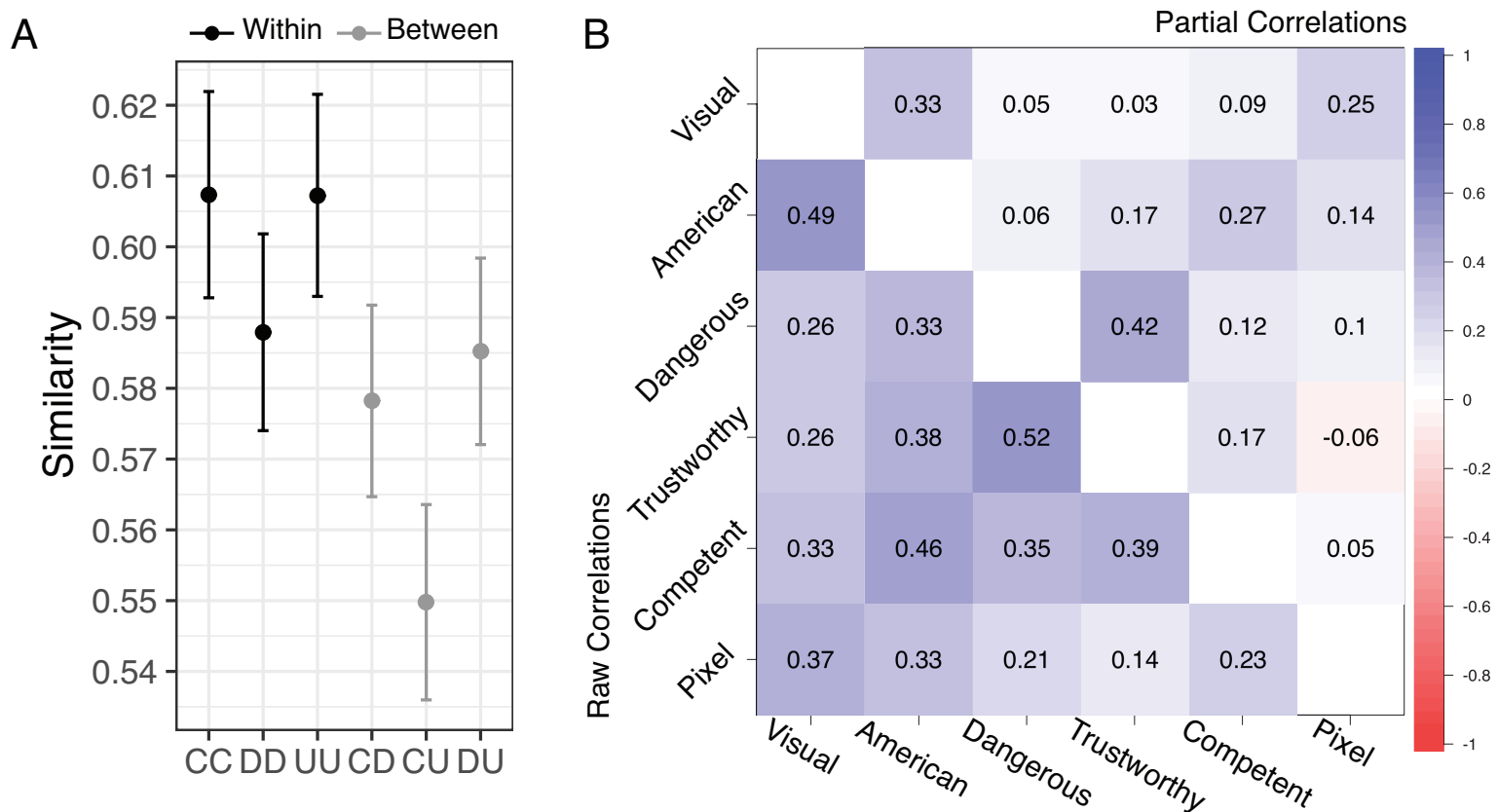

Figure 4. Documentation status visual similarities and relations between trait, sorting, and pixel similarities. A) Average sorting similarity scores between the various condition combinations of citizen (C), documented immigrant (D), and undocumented immigrant (U) faces. In grey are combinations we consider between category (e.g., citizen-undocumented; CU), in black are combinations considered to be within category (e.g., citizen-citizen; CC). Error bars represent $95 \%$ confidence intervals. B) Correlation matrix depicting the raw correlations between all the distance matrices in the bottom right triangle, the top right triangle represents the partial correlations. White diagonal are self-correlations.

Which cues facilitated the visual sorting of the faces' documentation statuses? We find that visual sorting similarity was most related to American similarity $(\rho=.49 \mathrm{CI}[.48, .51])$, followed by pixel similarity ( $\rho=.37 \mathrm{CI}[.36, .39])$, competence similarity $(\rho=.33 \mathrm{CI}[.31, .35])$, and the least to dangerous $(\rho=.26 \mathrm{CI}[.25, .28])$ and trustworthy $(\rho=.26 \mathrm{CI}[.24, .27])$ similarity (Figure 4B). The pixel similarity was also most related to American similarity ( $\rho=.33 \mathrm{CI}[.31, .34])$ and least to trustworthy similarity $(\rho=.14 \mathrm{CI}[.12, .15])$. The strong associations between visual sorting similarity, American similarity, and pixel similarity suggest that inferences about Americanness elicited by the faces and cues related to pixel luminance (e.g., skin color, highly contrasted facial features) helped participants sort the face set by documentation status. 
Examining the partial correlations disentangles these relations. After removing variance due to the visual similarity and all other trait similarities, the relationship between pixel similarity and American similarity dropped $(\rho=.14 \mathrm{CI}[.12, .16])$. Removing the variance due to pixel similarity (and all other trait similarities) also reduced the relationship between the visual similarity and American similarity ( $\rho=.33 \mathrm{CI}[.31, .34])$, yet the relationship remained large in magnitude. These findings suggest the visual sorting decisions were not made purely based on pixel information alone, but more so from evaluations of Americanness that perceivers imposed on the pixels themselves.

\section{Discussion}

Absent an explicit trait evaluation task, participants were able to sort the face representations such that faces who shared a documentation status were more similar than faces across statuses. While we did not directly measure the specific facial features used for sorting, we were able to infer that information using measures from the faces themselves (i.e., pixel luminance) and ratings of the same faces by the raters in Study 1. Supporting our conclusions that mental representations of documentation statuses are racialized, the similarity between faces on their low-level pixel luminance and on ratings of their Americanness were highly correlated with their similarity in the sorting task. Such associations highlight the influence of skin color and other low-level phenotypic cues in mental representations of documentation statuses.

\section{General Discussion}

We characterized what illegalized immigrants are thought to look like by assessing face representations. With the use of reverse correlation, we found meaningful differences in how certain facial phenotypes are thought to represent different documentation statuses. The resulting images are consistent with the racialized construction of migrant illegality in the history of U.S. 
imperialism (Ngai, 2004; Sáenz \& Manges Douglas, 2015; Sanchez \& Romero, 2010). Visualizations of illegalized immigrants were perceived to be non-white (or more so black), less American, trustworthy, competent, and more dangerous than visualizations of documented immigrants and U.S. citizens. These cues are robustly perceived as participants were able to sort the unlabeled representations by documentation status in a similarity sorting task. The citizen and undocumented immigrant faces were sorted into their own respective categories. This sorting performance was facilitated by visual information held in the faces (i.e., pixel luminance) and social information inferred from the faces (i.e., American-ness). We supplement the scholarship on the material racialization of illegalized immigrants (e.g., deportation, detention, incarceration) by describing the accompanying racialization that occurs in minds.

\section{Representing illegality}

Although there are historical and political associations between illegality and Mexicans and Latinxs more generally (Flores \& Schachter, 2018; Lee \& Fiske, 2006), the visualization of "undocumented" immigrants was perceived most likely to be black. There are a couple of possibilities for why this pattern emerged. The first accepts that face representations can act as a direct measure of nationality or race categories: maybe the association between Mexican/Latinxillegal has been replaced such that the darker-skinned face visualization reflects illegalized immigrants from what are perceived to be black-majority countries (e.g., Nigeria or Haiti). This possibility relies on bio-essentialist assumptions about what Mexicans look like (i.e., not dark skinned) and the range of nationalities that darker skin could signal. The second possibility rejects that face representations are a direct measure of nationality or race by acknowledging phenotypic variation: if one is thinking of a Mexican when visualizing illegalized immigrants, they are simply not thinking about lighter-skinned Mexicans. A third option is that the 
representation reflects a generic darker-skinned person without a specific national origin (e.g., anyone from the Global South). These possibilities all highlight the role of colorism in representations of migrant illegality; there are visual logics operating in tandem with categorical associations. Future research should clarify the relationship between categorical and visual representations of illegality.

\section{Where are these representations produced?}

Migrant illegality as a socially meaningful category is reified by a complex web of institutional actions and actors (e.g., laws, courts, judges), public and legislative discourses (e.g., threat propaganda, criminalizing policies), objects (e.g., visas, passports), geographies (e.g., borders, segregated neighborhoods), and social practices (e.g., surveillance, deportation). Here, we consider a few potential sources that could produce the visual face representations we identified in this study.

A commonly theorized source of information that shapes attitudes towards a social category is intergroup contact (Pettigrew, 1998). Illegalized immigrants are included in their communities through discretionary and contradictory laws or enforcement practices at national, state, and local levels (Andrews, 2017; Chauvin \& Garcés-Mascareñas, 2014). However, this does not guarantee that contact is extensive or even registered as contact with an illegalized immigrant unless they have disclosed their status. As evidence of this, self-reported measures of contact with illegalized immigrants suggest it is perceived as a rare occurrence (see Supplementary Table S1, S2, and S3). The lack of perceived contact suggests that understandings of illegalized immigrants are less likely to develop from direct social interactions and more from other readily available sources, such as media portrayals. 
Our university sample was collected at a time where there was campus activism that reached the highest courts of the U.S. alongside local storytelling from illegalized immigrants in the student body. Such an environment flooded the campus with positive media images of illegalized immigrants. Yet, our sample of students largely visualized illegalized immigrants as relatively dangerous, incompetent, and untrustworthy. One possibility for this mismatch is that the local discourse subtyped specific kinds of achieving illegalized immigrants as good (i.e., DACA recipients), leaving perceptions of the larger category (i.e., undocumented immigrants) intact.

Another possibility is that criminalizing media at the national level overpowered local discourse as a single criminal portrayal can taint perceptions of an entire group (Akalis et al., 2008). Despite consistent evidence that immigrants do not increase crime (Ousey \& Kubrin, 2018), news coverage of immigrants tends to be overwhelmingly crime-related (Abrajano \& Hajnal, 2015; Chavez, 2013). This media apparatus that produces the "criminal immigrant narrative" also psychologically embeds immigrants into racial hierarchies (Martinez et al., 2021). In support of this idea, the additional data we collected from an online sample located in border states (i.e., California and Texas) showed a highly similar racialized representation of illegalized immigrants as those from our university sample (Supplementary Figure S1).

Official government statistics about criminal behavior and demographic characteristics are yet another publicly available source that can set expectations about illegalized immigrants (Inda, 2006; Martinez et al., 2017, 2021). However, it is important to place this information in context. The enterprise of statistically characterizing illegalized immigrants has been fraught with problems. Initial attempts at enumeration often amounted to mere guesses that contributed to the construction of illegalized immigrants as a growing problem (Inda, 2006). Immigrants' 
avoidance of system legibility also subverts numeric estimates (Asad, 2020). Statistics about criminality have been inflated to an unknown extent by laws that have expanded the scope of criminality and deportability to include lesser infractions and retroactive charges (Warner, 2005). Official statistics may therefore reflect how incarceration, racialization, and illegalization are intertwined in population control projects (Stumpf, 2006), rather than characterizing the social reality of a category with continuously shifting boundaries.

\section{Implications}

Our results identify that facial phenotype is an important feature used in ascriptions of illegality, one that cannot be changed by immigrants themselves. This may be why illegalized immigrants enact alternative strategies for "legal passing" in daily life, which includes carefully choosing modifiable cues: public apparel, behavior, annunciations, and even transportation options (Garcia, 2019). The use of face cues to detect illegality could play a role in why both illegalized immigrants and U.S. citizens who match the visual representation become targets of mobilized hate crimes and deportation procedures (Ismay, 2019; Rosenberg, 2019).

Our results also speak to the role of language in perceptions of illegality. Research and immigrant activism focused on labeling effects suggest that "undocumented" is a strategically better term than "illegal" in that it is less threatening and facilitates pro-immigrant policy preferences (Ommundsen et al., 2014; Rucker et al., 2019). Although we did not examine "illegal" representations, one could predict that they might conjure a worse, if not the same, kind of visualization as "undocumented". That "undocumented" was enough to visualize a racialized threat suggests that the illegal/undocumented dichotomy is too mired in criminalization to reclaim. Language activism may ultimately need to be (re)connected to broader struggles against racializing and criminalizing institutions (Rosa, 2019a). For instance, using labels that 
productively redirect the origin of illegal status away from immigrants themselves towards institutions that criminalize movement. One recent candidate that we have used throughout this paper is "illegalized immigrants" (Bauder, 2014).

\section{Limitations}

While we focused on representations of immigrant men from the perspective that they have been critical targets of the current deportation regime (Golash-Boza \& Hondagneu-Sotelo, 2013), more recent national conversations have centered around family and child separation at the border, highlighting how racial and gender projects can shift. These developments suggest that broadening the demographic characteristics of the base face (e.g., women, children) could capture alternative understandings of migrant illegality.

\section{Conclusions}

Given that movement in an increasingly globalized world has become increasingly restricted, illegality continues to be forced upon migrating populations. This work reflects an initial examination into visual representations of illegalized immigrants. However, visual logics are only one dimension that reifies illegalization in the social arena. Other dimensions (e.g., linguistic, aural, olfactory, ancestral, geographic, material, cultural) must also be examined for a better understanding of the continuing construction of this classification (e.g., Rosa, 2019b; Schachter et al., 2021). Monitoring how these representations shift with time and across geographies can provide a necessary window into the way that imperial projects imprint conceptualizations of illegality in the public mind.

\section{Acknowledgements}


We would like to thank Brandon Labbree for their help with data collection and the Society for Personality and Social Psychology's "Inside the Grant Panel" grant for helping fund this research. 


\section{References}

Abrajano, M., \& Hajnal, Z. (2015). White backlash: Immigration, race, and American politics. Princeton University Press.

Abrego, L. J., \& Negrón-Gonzales, G. (Eds.). (2020). We are not dreamers: Undocumented scholars theorize undocumented life in the United States. Duke University Press.

Ackerman, E. F. (2013). The Rise of the "Illegal Alien.” Contexts, 12(3), 72-74. https://doi.org/10.1177/1536504213499883

Akalis, S. A., Banaji, M. R., \& Kosslyn, S. M. (2008). CRIME ALERT! How Thinking about a Single Suspect Automatically Shifts Stereotypes toward an Entire Group. Du Bois Review, 217-233.

Alamillo, R., Haynes, C., \& Madrid, R. (2019). Framing and immigration through the trump era. Sociology Compass, 13(5), e12676. https://doi.org/10.1111/soc4.12676

Alter, A. L., Stern, C., Granot, Y., \& Balcetis, E. (2016). The "Bad Is Black” Effect: Why People Believe Evildoers Have Darker Skin Than Do-Gooders. Personality and Social Psychology Bulletin, 42(12), 1653-1665. https://doi.org/10.1177/0146167216669123

American Immigration Council. (2020). The Dream Act, DACA, and Other Policies Designed to Protect Dreamers. American Immigration Council. https://www.americanimmigrationcouncil.org/research/dream-act-daca-and-otherpolicies-designed-protect-dreamers

Andrews, A. L. (2017). Moralizing regulation: The implications of policing "good" versus "bad" immigrants. Ethnic and Racial Studies, 0(0), 1-19.

https://doi.org/10.1080/01419870.2017.1375133 
Asad, A. L. (2020). On the Radar: System Embeddedness and Latin American Immigrants' Perceived Risk of Deportation. Law \& Society Review, 54(1), 133-167. https://doi.org/10.1111/lasr.12460

Barr, D. J., Levy, R., Scheepers, C., \& Tily, H. J. (2013). Random effects structure for confirmatory hypothesis testing: Keep it maximal. Journal of Memory and Language, 68(3), 255-278. https://doi.org/10.1016/j.jml.2012.11.001

Bates, D. M., Mächler, M., Bolker, B., \& Walker, S. (2015). Fitting linear mixed-effects models using lme4. Journal of Statistical Software, 67(1), 1-48. https://doi.org/10.18637/jss.v067.i01

Bauder, H. (2014). Why We Should Use the Term “Illegalized” Refugee or Immigrant: A Commentary. International Journal of Refugee Law, 26(3), 327-332. https://doi.org/10.1093/ijrl/eeu032

Blinder, S. (2015). Imagined immigration: The impact of different meanings of 'immigrants' in public opinion and policy debates in Britain. Political Studies, 63(1), 80-100. https://doi.org/10.1111/1467-9248.12053

Brinkman, L., Goffin, S., van de Schoot, R., van Haren, N. E. M., Dotsch, R., \& Aarts, H. (2019). Quantifying the informational value of classification images. Behavior Research Methods, 51(5), 2059-2073. https://doi.org/10.3758/s13428-019-01232-2

Brinkman, L., Todorov, A., \& Dotsch, R. (2017). Visualising mental representations: A primer on noise-based reverse correlation in social psychology. European Review of Social Psychology, 28(1), 333-361. https://doi.org/10.1080/10463283.2017.1381469 
Brown, H. E. (2013). Race, legality, and the social policy consequences of anti-immigration mobilization. American Sociological Review, 78(2), 290-314. https://doi.org/10.1177/0003122413476712

Brown-Iannuzzi, J. L., Dotsch, R., Cooley, E., \& Payne, B. K. (2017). The relationship between mental representations of welfare recipients and attitudes toward welfare. Psychological Science, 28(1), 92-103. https://doi.org/10.1177/0956797616674999

Brubaker, R., Loveman, M., \& Stamatov, P. (2004). Ethnicity as cognition. Theory and Society, 33(1), 31-64. https://doi.org/10.1023/B:RYSO.0000021405.18890.63

Chauvin, S., \& Garcés-Mascareñas, B. (2012). Beyond Informal Citizenship: The New Moral Economy of Migrant Illegality. International Political Sociology, 6(3), 241-259. https://doi.org/10.1111/j.1749-5687.2012.00162.x

Chauvin, S., \& Garcés-Mascareñas, B. (2014). Becoming Less Illegal: Deservingness Frames and Undocumented Migrant Incorporation. Sociology Compass, 8(4), 422-432. https://doi.org/10.1111/soc4.12145

Chavez, L. R. (2013). The Latino threat: Constructing immigrants, citizens, and the nation (Second edition). Stanford University Press.

Cone, J., Brown-Iannuzzi, J. L., Lei, R., \& Dotsch, R. (2020). Type I Error Is Inflated in the Two-Phase Reverse Correlation Procedure. Social Psychological and Personality Science, 194855062093861. https://doi.org/10.1177/1948550620938616

Costanza-Chock, S. (2014). Out of the shadows, into the streets! Transmedia organizing and the immigrant rights movement. The MIT Press.

De Genova, N. (2004). The legal production of Mexican/migrant “"illegality.”' Latino Studies, 2, $160-185$. 
De Genova, N. P. (2002). Migrant "Illegality” and Deportability in Everyday Life. Annual Review of Anthropology, 31(1), 419-447. https://doi.org/10.1146/annurev.anthro.31.040402.085432

DeBruine, L., \& Jones, B. (2017). Face Research Lab London Set (p. 281699312 Bytes) [Data set]. figshare. https://doi.org/10.6084/M9.FIGSHARE.5047666.V3

Devos, T., \& Banaji, M. R. (2005). American = White? Journal of Personality and Social Psychology, 88(3), 447-466. https://doi.org/10.1037/0022-3514.88.3.447

Dobs, K., Isik, L., Pantazis, D., \& Kanwisher, N. (2019). How face perception unfolds over time. Nature Communications, 10(1), 1258. https://doi.org/10.1038/s41467-019-09239-1

Dotsch, R. (2017). rcicr: Reverse correlation image classification toolbox. (R package version 0.4.0) [Computer software].

Dotsch, R., \& Todorov, A. (2012). Reverse correlating social face perception. Social Psychological and Personality Science, 3(5), 562-571. https://doi.org/10.1177/1948550611430272

Eberhardt, J. L., Goff, P. A., Purdie, V. J., \& Davies, P. G. (2004). Seeing Black: Race, Crime, and Visual Processing. Journal of Personality and Social Psychology, 87(6), 876-893. https://doi.org/10.1037/0022-3514.87.6.876

Fields, K. E., \& Fields, B. J. (2012). Racecraft: The soul of inequality in American life. Verso. Flores, R. D., \& Schachter, A. (2018). Who are the "illegals"? The social construction of illegality in the United States. American Sociological Review, 83(5), 839-868.

Garcia, A. S. (2019). Legal passing: Navigating undocumented life and local immigration law. University of California Press. 
Gilens, M. (1996). "Race coding” and white opposition to welfare. American Political Science Review, 90(3), 593-604. https://doi.org/10.2307/2082611

Golash-Boza, T. M. (2015). Deported: Immigrant policing, disposable labor, and global capitalism. https://doi.org/10.1111/imre.12272

Golash-Boza, T. M., \& Hondagneu-Sotelo, P. (2013). Latino immigrant men and the deportation crisis: A gendered racial removal program. Latino Studies, 11(3), 271-292. https://doi.org/10.1057/lst.2013.14

Green, P., \& Macleod, C. J. (2016). SIMR: An R package for power analysis of generalized linear mixed models by simulation. Methods in Ecology and Evolution, 7(4), 493-498. https://doi.org/10.1111/2041-210X.12504

Inda, J. X. (2006). Targeting immigrants: Government, technology, and ethics. Blackwell Pub. Ismay, J. (2019). Victim of Milwaukee Acid Attack Says He Was Told to 'Go Back to Your Country’ (Published 2019). The New York Times. https://www.nytimes.com/2019/11/04/us/milwaukee-acid-attack-victim.html

Jaeger, B., Todorov, A. T., Evans, A. M., \& van Beest, I. (2020). Can we reduce facial biases? Persistent effects of facial trustworthiness on sentencing decisions. Journal of Experimental Social Psychology, 90, 104004. https://doi.org/10.1016/j.jesp.2020.104004

Koch, A., Speckmann, F., \& Unkelbach, C. (2020). Q-SpAM: How to Efficiently Measure Similarity in Online Research. Sociological Methods \& Research, 1-23. https://doi.org/10.1177/0049124120914937

Kriegeskorte, N., Mur, M., \& Bandettini, P. (2008). Representational similarity analysisConnecting the branches of systems neuroscience. Frontiers in Systems Neuroscience, 2(November), 4-4. https://doi.org/10.3389/neuro.06.004.2008 
Kunst, J. R., Dovidio, J. F., \& Dotsch, R. (2017). White Look-Alikes: Mainstream Culture Adoption Makes Immigrants “Look” Phenotypically White. Personality and Social Psychology Bulletin, 014616721773927-014616721773927.

https://doi.org/10.1177/0146167217739279

Lauby, F. (2016). Leaving the 'perfect DREAMer' behind? Narratives and mobilization in immigration reform. Social Movement Studies, 15(4), 374-387.

https://doi.org/10.1080/14742837.2016.1149461

Lee, T. L., \& Fiske, S. T. (2006). Not an outgroup, not yet an ingroup: Immigrants in the Stereotype Content Model. International Journal of Intercultural Relations, 30(6), 751768. https://doi.org/10.1016/j.ijintrel.2006.06.005

Lenth, R. V. (2020). emmeans: Estimated Marginal Means, aka Least-Squares Means. (R package version 1.5.3) [Computer software]. https://github.com/rvlenth/emmeans

Lord, C. G., Desforges, D. M., Fein, S., Pugh, M., \& et al. (1994). Typicality effects in attitudes toward social policies: A concept-mapping approach. Journal of Personality and Social Psychology, 66(4), 658-673. https://doi.org/10.1037/0022-3514.66.4.658

Maddox, K. B. (2004). Perspectives on Racial Phenotypicality Bias. Personality and Social Psychology Review, 8(4), 383-401. https://doi.org/10.1207/s15327957pspr0804_4

Maddox, K. B., \& Perry, J. M. (2018). Racial appearance bias: Improving evidence-based policies to address racial disparities. Policy Insights from the Behavioral and Brain Sciences, 5(1), 57-65. https://doi.org/10.1177/2372732217747086

Martinez, J. E., Feldman, L. A., \& Cikara, M. (2017). Showcasing immigrant excellence. Scientific American. https://blogs.scientificamerican.com/guest-blog/showcasingimmigrant-excellence/ 
Martinez, J. E., Feldman, L. A., Feldman, M. J., \& Cikara, M. (2021). Narratives shape cognitive representations of immigrants and immigration-policy preferences. Psychological Science, 1-18. https://doi.org/10.1177/0956797620963610

Menjívar, C., \& Kanstroom, D. (Eds.). (2014). Constructing immigrant “illegality”: Critiques, experiences, and responses. Cambridge University Press.

New American Economy. (2020). Undocumented students in higher education. https://research.newamericaneconomy.org/wpcontent/uploads/sites/2/2020/04/HigherEd_brief_V3-1.pdf

Ngai, M. M. (2004). Impossible subjects: Illegal aliens and the making of modern America. Princeton University Press.

Nicolas, G., \& Skinner, A. L. (2017). Constructing race: How people categorize others and themselves in racial terms. In Handbook of Categorization in Cognitive Science (pp. 607635). Elsevier. https://doi.org/10.1016/B978-0-08-101107-2.00025-7

Ommundsen, R., Larsen, K. S., van der Veer, K., \& Eilertsen, D.-E. (2014). Framing Unauthorized Immigrants: The Effects of Labels on Evaluations. Psychological Reports, 114(2), 461-478. https://doi.org/10.2466/17.PR0.114k20w0

Oosterhof, N. N., \& Todorov, A. (2008). The functional basis of face evaluation. Proceedings of the National Academy of Sciences of the United States of America, 105(32), 1108711092. https://doi.org/10.1073/pnas.0805664105

Ousey, G. C., \& Kubrin, C. E. (2018). Immigration and Crime: Assessing a Contentious Issue. Annual Review of Criminology, 1(1), 63-84. https://doi.org/10.1146/annurev-criminol032317-092026 
Passel, J. S., \& Cohn, D. (2019). Mexicans decline to less than half the U.S. unauthorized immigrant population for the first time. Pew Research Center. https://www.pewresearch.org/fact-tank/2019/06/12/us-unauthorized-immigrantpopulation-2017/

Pérez, E. O. (2010). Explicit Evidence on the Import of Implicit Attitudes: The IAT and Immigration Policy Judgments. Political Behavior, 32(4), 517-545. https://doi.org/10.1007/s11109-010-9115-z

Pettigrew, T. F. (1998). Intergroup contact theory. Annual Review of Psychology, 49(July), 6585. https://doi.org/10.1146/annurev.psych.49.1.65

Pon, A. (2018). The Dreamer Divide: Aspiring for a More Inclusive Immigrants’ Rights Movement. Stanford Journal of Civil Rights and Liberties, 14(SI33).

Princeton University Office of Communications. (2020). Princeton, Microsoft, Maria Perales Sanchez '18 welcome Supreme Court ruling to restore DACA. Princeton University. https://www.princeton.edu/news/2020/06/18/princeton-microsoft-maria-perales-sanchez18-welcome-supreme-court-ruling-restore

Provine, D. M., \& Doty, R. L. (2011). The criminalization of immigrants as a racial project. Journal of Contemporary Criminal Justice, 27(3), 261-277. https://doi.org/10.1177/1043986211412559

R Core Team. (2015). R: A language and environment for statistical computing. R Foundation for Statistical Computing. http://www.r-project.org/

Revelle, W. (2018). psych: Procedures for Psychological, Psychometric, and Personality Research (R package verison 1.8.12) [Computer software]. https:/CRAN.Rproject.org/package $=$ psych 
Rosa, J. (2019a). Contesting Representations of Migrant "Illegality" through the Drop the IWord Campaign Rethinking Language Change and Social Change. In N. Avineri, L. R. Graham, E. J. Johnson, R. Conley Riner, \& J. Rosa (Eds.), Language and social justice in practice (pp. 35-43). Routledge.

Rosa, J. (2019b). Looking like a language, sounding like a race: Raciolinguistic ideologies and the learning of Latinidad. Oxford University Press.

Rosenberg, E. (2019). A Latino Marine veteran was detained for deportation. Then ICE realized he was a citizen. Washington Post. https:/www.washingtonpost.com/nationalsecurity/2019/01/17/latino-marine-veteran-was-detained-deportation-then-ice-realizedhe-was-citizen/

Rucker, J. M., Murphy, M. C., \& Quintanilla, V. D. (2019). The immigrant labeling effect: The role of immigrant group labels in prejudice against noncitizens. Group Processes \& Intergroup Relations, 136843021881874. https://doi.org/10.1177/1368430218818744

Sáenz, R., \& Manges Douglas, K. (2015). A Call for the Racialization of Immigration Studies: On the Transition of Ethnic Immigrants to Racialized Immigrants. Sociology of Race and Ethnicity, 1(1), 166-180. https://doi.org/10.1177/2332649214559287

Sanchez, G., \& Romero, M. (2010). Critical Race Theory in the US Sociology of Immigration: Critical Race Theory in the US Sociology. Sociology Compass, 4(9), 779-788. https://doi.org/10.1111/j.1751-9020.2010.00303.x

Santa Ana, O. (1997). Empirical analysis of anti-immigrant metaphor in political discourse. University of Pennsylvania Working Papers in Linguistics, 4(1), 317-330. 
Schachter, A., Flores, R. D., \& Maghbouleh, N. (2021). Ancestry, color, or culture? How whites racially classify others in the U.S. American Journal of Sociology, 126(5), 1220-1263. https://doi.org/10.1086/714215

Stolier, R. M., Hehman, E., \& Freeman, J. B. (2020). Trait knowledge forms a common structure across social cognition. Nature Human Behaviour, 4(4), 361-371. https://doi.org/10.1038/s41562-019-0800-6

Stumpf, J. P. (2006). The crimmigration crisis: Immigrants, crime, and sovereign power. In J. A. Dowling \& J. X. Inda (Eds.), Governing Immigration Through Crime (pp. 59-76). Stanford University Press. https://doi.org/10.1515/9780804785419-004

Swerts, T., \& Nicholls, W. (2020). Undocumented Immigrant Activism and the Political: Disrupting the Order or Reproducing the Status Quo? Antipode, anti.12678. https://doi.org/10.1111/anti.12678

Todorov, A. (2017). Face value: The irresistible influence of first impressions. Princeton University Press.

Todorov, A., Olivola, C. Y., Dotsch, R., \& Mende-Siedlecki, P. (2015). Social Attributions from Faces: Determinants, Consequences, Accuracy, and Functional Significance. Annual Review of Psychology, 66, 519-545. https://doi.org/10.1146/annurev-psych-113011143831

Warner, J. A. (2005). The social construction of the criminal alien in immigration law, enforcement practice and statistical enumeration: Consequences for immigrant stereotyping. Journal of Social and Ecological Boundaries, 1.2, 56-80.

Waters, M., \& Kasinitz, P. (2015). The war on crime and the war on immigrants: Racial and legal exclusion in the twenty-first-century United States. In Fear, anxiety, and national 
identity: Immigration and belonging in North America and Western Europe. Russell Sage Foundation.

Wenner, A. (2018, March 16). Journeys of hardship and hope: DACA students share their stories. Princeton Alumni Weekly. https://paw.princeton.edu/article/journeys-hardshipand-hope-daca-students-share-their-stories

Westfall, J. (2016). Five different “Cohen's d" statistics for within-subject designs. http://jakewestfall.org/blog/index.php/category/effect-size/

Willis, J., \& Todorov, A. (2006). Making up your mind after 100-ms Exposure to Face. Psychological Science, 17(7), 592-598. https://doi.org/10.1111/j.14679280.2006.01750.x

Yukich, G. (2013). Constructing the Model Immigrant Movement Strategy and Immigrant Deservingness in the New Sanctuary Movement. Social Problems, 60(3), 302-320. https://doi.org/10.1525/sp.2013.60.3.302

Zatz, M. S., \& Rodriguez, N. (2015). Dreams and nightmares: Immigration policy, youth, and families (First edition). University of California Press. 


\section{Immigrant face-ism: documentation statuses evoke racialized cognitive representations - Supplementary materials}

Table of contents:

- Appendix A. Differences from pre-registration

- Supplementary Figure S1. Comparisons between Princeton and Amazon Mechanical Turk (MTurk) samples' representations of undocumented immigrant

- Supplementary Figure S2. Similarity Matrices.

- Supplementary Table S1. Participant demographics in Study 1, average face ratings

- Supplementary Table S2. Participant demographics in Study 1, individual face ratings

- Supplementary Table S3. Participant demographics in Study 2, similarity sorting task

- Supplementary Table S4. Correlations between similarity matrices. 


\section{Appendix}

\section{Appendix A. Differences from pre-registration}

The overall project centered on a descriptive examination of representations, so the preregistration was more general than what a confirmatory test would require. We list all deviations from the pre-registration in the followings:

- We stated that we would have the faces rated on how "foreign" they were perceived. After preregistering, we realized that this dimension could be unspecific in its referents (e.g., foreign from what vantage point and towards which direction?) and decided that "American" would be a more direct test of what we were interested in: inferences about their belongingness to the U.S. We did not collect ratings of "foreignness".

- We stated that we would collect 120 total participants in the image generating task (40 in each documentation status condition). Our final sample instead contained 50 participants in each condition, totaling up to 150 participants.

- We stated that we would exclude faces with an InfoVal of less than or equal to 1.56. An InfoVal is a numeric metric aimed at quantifying the informational value of a reverse correlation classification image (Brinkman et al., 2019). At the time of pre-registration, the InfoVal metric was yet to be published but reflected a novel and promising way to assess image reliability. However, while collecting data, we found that images that passed the 1.56 and more so the recommended 1.96 criterion were rare. We stopped data collection at 181 participants $(\mathrm{N}=59$ citizen, $\mathrm{N}=70$ documented, $\mathrm{N}=51$ undocumented), and reassessed whether the exclusion criterion was too stringent. In order to ethically not discard a large amount of the data set that could be used, we decided to choose 50 faces from each condition from the data we had collected. These 50 faces would include those with the highest InfoVal scores, even if they were below criterion. So, the final sample included 150 total faces (50 from each condition), and through this procedure, 31 faces were excluded, those with the lowest InfoVal. Our difficulty obtaining high InfoValscoring faces reflect multiple possibilities. Maybe documentation statuses are not collectively solidified as visual stereotypes of gender categories are (gender was used to validate the InfoVal metric in Brinkman et. al. 2019). Another possibility is that our sample happened to collect unreliable data because of student characteristics or because our task was too difficult with 770 trials. In order to understand how our alternative exclusion procedure might have affected the resulting images, we created a classification image from only the faces that surpassed the InfoVal criterion in the undocumented immigrant condition (see image below). Both faces look nearly identical, suggesting that our average results in Study 1 would have been highly similar with the subset of only reliable images. This pattern suggests that the lower InfoVal-scoring images in our sample contribute little to the overall average. Lastly, this suggests that our individual classification face rating results in Study 1 are more conservative in that the results were obtained using individual face images that may have washed out any potential differences between conditions. 
Final Sample

$\mathrm{N}=50$

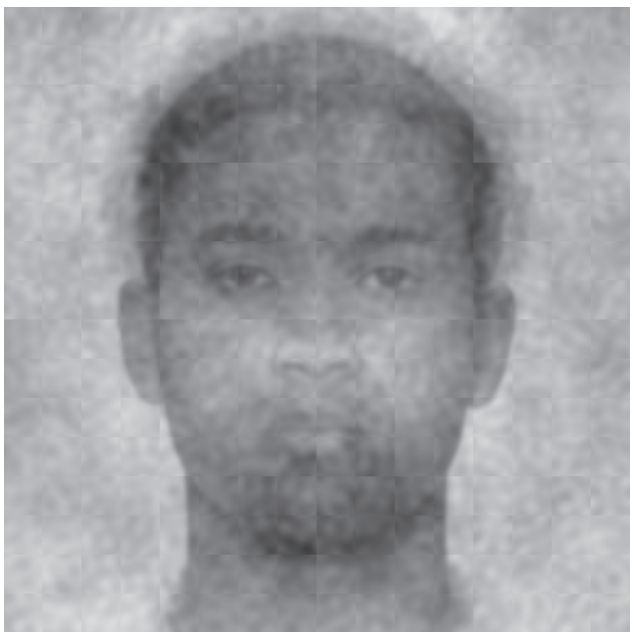

High InfoVal Only

$\mathrm{N}=25$

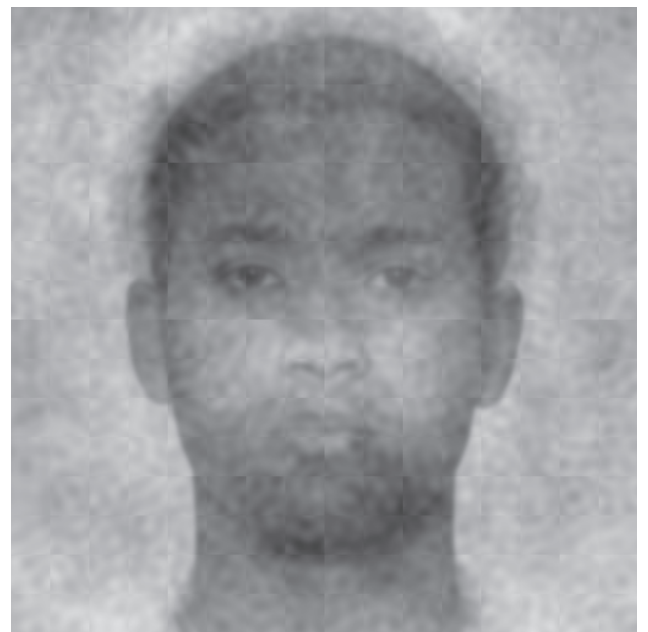

- We stated that the results of a power simulation with a hypothesized large effect size of $f=.77$ for the dangerous ratings that 20 participants would be enough for almost $100 \%$ power. Knowing that rating data from online samples is not always reliable, we stated that we would instead collect 40 participants per rating task in order to account for likely reliability exclusions. We achieved this sample size for the average classification image ratings which ended up exhibiting even larger effect sizes than .77. However, for the individual faces the sample sizes were often in the mid 30s, which is still above 20 participants, the minimum requirement estimated by our simulations. See figure below that tested how the number of participants affect power from the simulated model.

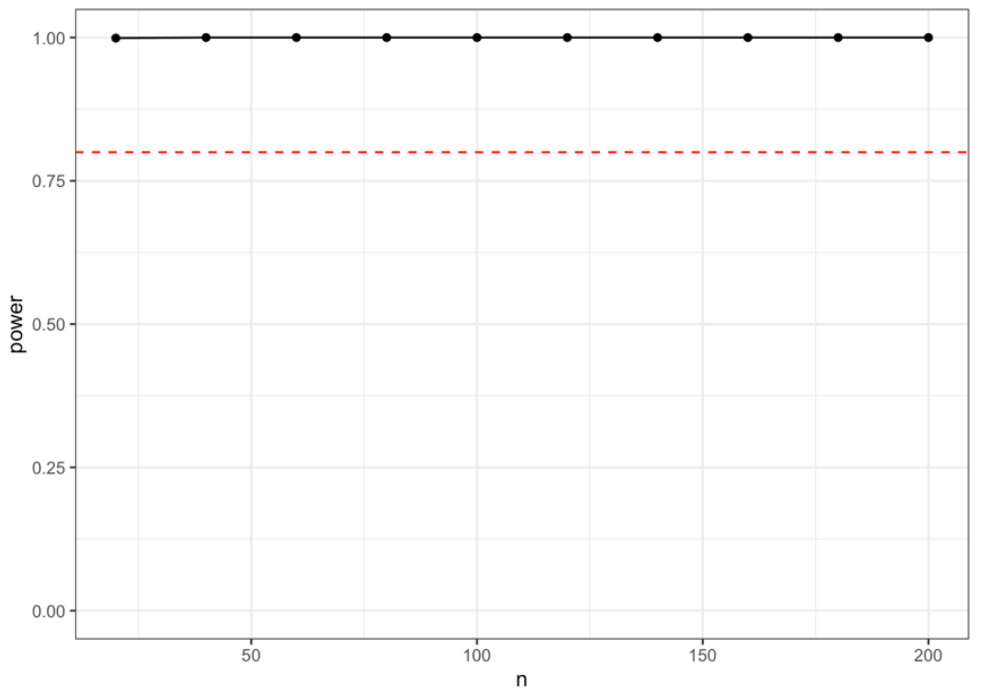

- We stated that we would collect 200 participants for the similarity sorting task, we instead collected 201 participants. The extra participant was a pilot participant to make sure the task worked. Since there were no issues, we decided to include them in the full sample. 
A)

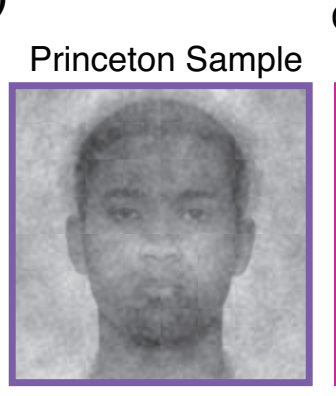

California \& Texas MTurk Sample

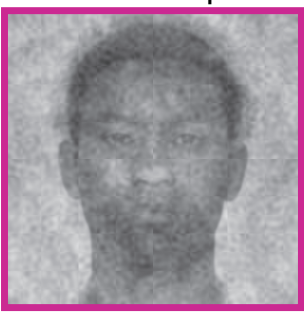

B)

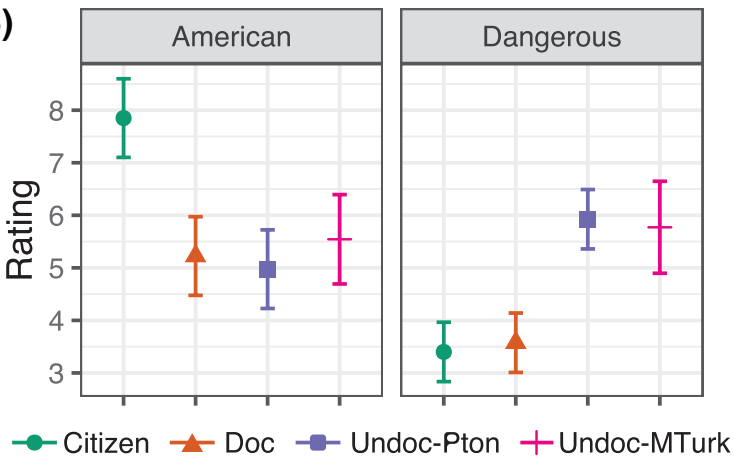

Supplementary Figure S1. Comparisons between Princeton and Amazon Mechanical Turk (MTurk) samples' representations of "undocumented immigrant". A) The average classification image from a Princeton sample $(\mathrm{N}=50)$ and an MTurk sample $(\mathrm{N}=1002)$. B) Average American and dangerous ratings given to the average faces from this project (from Figure 2) and the average face from the MTurk sample (pink). Error bars represent $95 \%$ confidence intervals. The MTurk data were collected for a separate project and thus we only include measures from that project that overlap with this one (i.e., American and Dangerous ratings). The MTurk sample was located within California and Texas and thus represents representations from the U.S.-Mexico border, a geographically and socio-politically different area from the northeastern Princeton sample. Raters for the MTurk average face were also collected from MTurk (Dangerous $\mathrm{N}=58$, American $\mathrm{N}=46$ ). Participants completed 300 trials in the reverse correlation task with the same base face and stimulus pairs as this project. The MTurk average face was also ethnoracially classified ( $\mathrm{N}=87$ MTurkers), however using a simple multiple forced choice measure rather than the likelihood measure from this study. The face was categorized as "black" by $82 \%$ of the sample followed by "Asian" by $9 \%$ of the sample. 

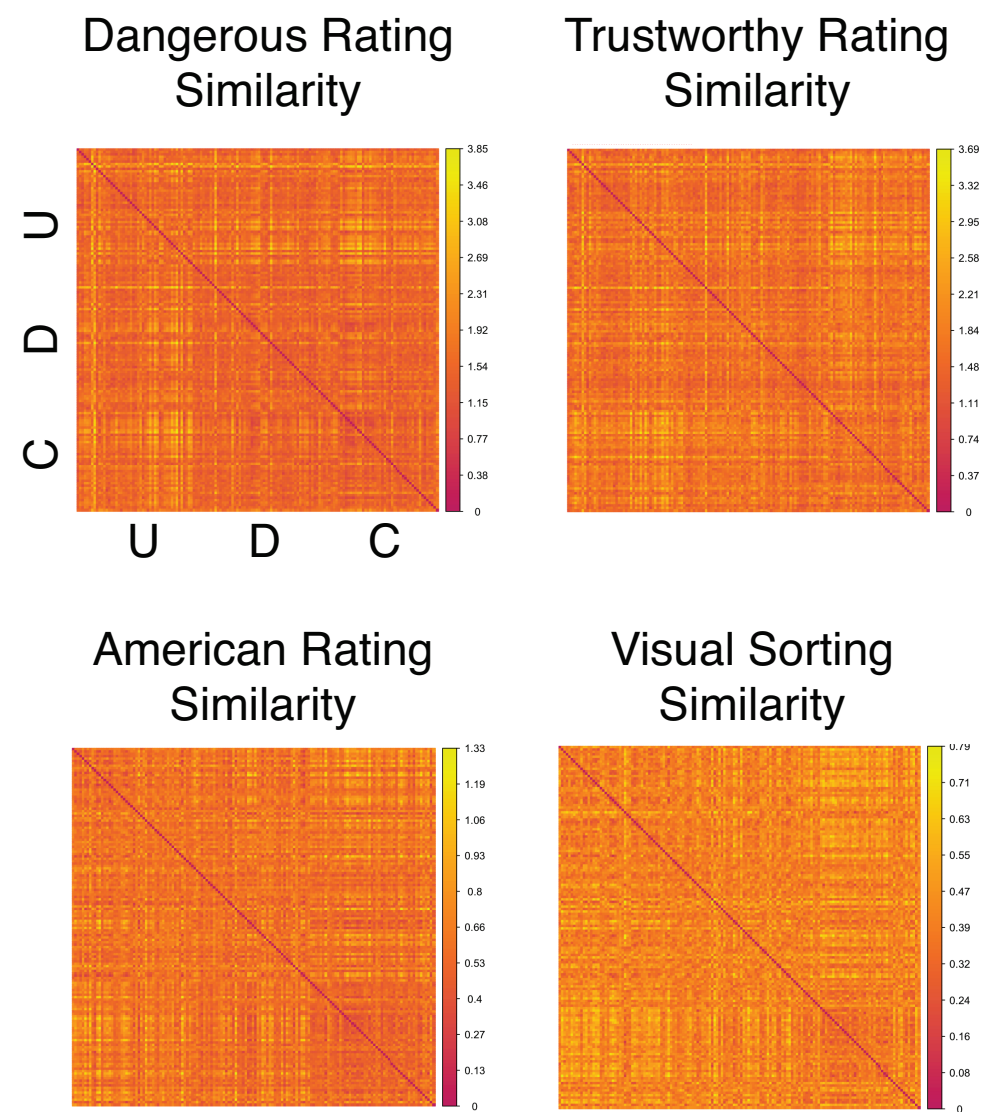

\section{Competent Rating} Similarity

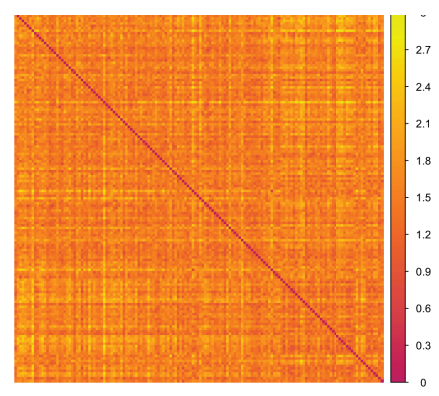

Pixel

Similarity

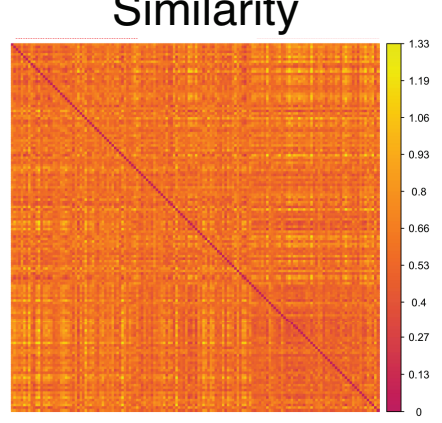

Supplementary Figure S2. Similarity matrices. Similarity matrices where the rows and columns represent all the individual classification images in top-down order from undocumented immigrant (U), documented immigrant (D), to citizen (C) as approximately depicted on the dangerous matrix. Darker red colors represent more similar faces, and lighter yellow colors are more dissimilar faces. Each matrix, except the pixel matrix, was created from separate samples who rated the same faces. 
Supplementary Table S1. Participant demographics for Study 1, average face ratings

\begin{tabular}{|c|c|c|c|c|c|}
\hline & $\begin{array}{c}\text { American } \\
(\mathbf{N}=\mathbf{4 0})\end{array}$ & $\begin{array}{c}\text { Competen } \\
\mathbf{t} \\
(\mathbf{N}=\mathbf{4 0})\end{array}$ & $\begin{array}{c}\text { Dangerous } \\
(\mathbf{N}=\mathbf{4 0})\end{array}$ & $\begin{array}{c}\text { Race } \\
(\mathrm{N}=\mathbf{4 0})\end{array}$ & $\begin{array}{c}\text { Trustwort } \\
\text { hy } \\
(\mathrm{N}=40)\end{array}$ \\
\hline \multicolumn{6}{|l|}{ Age } \\
\hline Mean (SD) & $40.7(13.2)$ & $36.1(10.6)$ & $37.4(12.1)$ & $36.2(9.62)$ & $39.3(11.6)$ \\
\hline Median [Min, Max] & $\begin{array}{c}38.5[24.0 \\
72.0]\end{array}$ & $\begin{array}{c}33.0[19.0, \\
68.0]\end{array}$ & $\begin{array}{c}35.0[22.0 \\
\quad 66.0]\end{array}$ & $\begin{array}{c}35.0[21.0 \\
64.0]\end{array}$ & $\begin{array}{c}38.0[18.0 \\
\quad 69.0]\end{array}$ \\
\hline \multicolumn{6}{|l|}{ Gender } \\
\hline Female & $19(47.5 \%)$ & $20(50.0 \%)$ & $17(42.5 \%)$ & $14(35.0 \%)$ & $16(40.0 \%)$ \\
\hline Male & $21(52.5 \%)$ & $20(50.0 \%)$ & $23(57.5 \%)$ & $26(65.0 \%)$ & $24(60.0 \%)$ \\
\hline \multicolumn{6}{|l|}{ Race } \\
\hline Asian/Pacific Islander & $1(2.5 \%)$ & $1(2.5 \%)$ & $4(10.0 \%)$ & $3(7.5 \%)$ & $2(5.0 \%)$ \\
\hline Black or African & $2(5.0 \%)$ & $3(7.5 \%)$ & $4(10.0 \%)$ & $2(5.0 \%)$ & $4(10.0 \%)$ \\
\hline Multiracial & $4(10.0 \%)$ & $0(0 \%)$ & $2(5.0 \%)$ & $2(5.0 \%)$ & $3(7.5 \%)$ \\
\hline White or European & $33(82.5 \%)$ & $33(82.5 \%)$ & $27(67.5 \%)$ & $31(77.5 \%)$ & $29(72.5 \%)$ \\
\hline Indigenous & $0(0 \%)$ & $1(2.5 \%)$ & $0(0 \%)$ & $0(0 \%)$ & $0(0 \%)$ \\
\hline Latinx/o/a or Hispanic & $0(0 \%)$ & $2(5.0 \%)$ & $3(7.5 \%)$ & $2(5.0 \%)$ & $2(5.0 \%)$ \\
\hline \multicolumn{6}{|l|}{ Was born in U.S. } \\
\hline No & $3(7.5 \%)$ & $2(5.0 \%)$ & $4(10.0 \%)$ & $3(7.5 \%)$ & $1(2.5 \%)$ \\
\hline Yes & $37(92.5 \%)$ & $38(95.0 \%)$ & $36(90.0 \%)$ & $37(92.5 \%)$ & $39(97.5 \%)$ \\
\hline \multicolumn{6}{|l|}{ Is U.S. citizen } \\
\hline No & $1(2.5 \%)$ & $0(0 \%)$ & $0(0 \%)$ & $1(2.5 \%)$ & $1(2.5 \%)$ \\
\hline Yes & $39(97.5 \%)$ & $40(100 \%)$ & $40(100 \%)$ & $39(97.5 \%)$ & $39(97.5 \%)$ \\
\hline \multicolumn{6}{|l|}{ Live in U.S. } \\
\hline I am living in the U.S. & $40(100 \%)$ & $40(100 \%)$ & $40(100 \%)$ & $39(97.5 \%)$ & $40(100 \%)$ \\
\hline I am living outside the US. & $0(0 \%)$ & $0(0 \%)$ & $0(0 \%)$ & $1(2.5 \%)$ & $0(0 \%)$ \\
\hline \multicolumn{6}{|l|}{$\begin{array}{l}\text { Immigrant } \\
\text { Contact a }\end{array}$} \\
\hline Mean (SD) & $2.60(1.46)$ & $3.53(2.00)$ & $3.40(2.01)$ & $3.65(1.90)$ & $3.30(1.86)$ \\
\hline Median [Min, Max] & $\begin{array}{c}2.00[1.00 \\
\quad 6.00]\end{array}$ & $\begin{array}{c}3.00[1.00 \\
\quad 7.00]\end{array}$ & $\begin{array}{c}2.50[1.00 \\
\quad 7.00]\end{array}$ & $\begin{array}{c}3.00[1.00 \\
\quad 7.00]\end{array}$ & $\begin{array}{c}3.00[1.00 \\
7.00]\end{array}$ \\
\hline \multicolumn{6}{|l|}{$\begin{array}{l}\text { Undocumented } \\
\text { Contact }^{b}\end{array}$} \\
\hline Mean (SD) & $1.73(1.06)$ & $2.60(1.63)$ & $2.40(1.91)$ & $2.40(1.53)$ & $2.13(1.30)$ \\
\hline Median [Min, Max] & $\begin{array}{c}1.00[1.00 \\
\quad 6.00]\end{array}$ & $\begin{array}{c}2.00[1.00 \\
\quad 7.00]\end{array}$ & $\begin{array}{c}2.00[1.00 \\
\quad 7.00]\end{array}$ & $\begin{array}{c}2.00[1.00 \\
\quad 7.00]\end{array}$ & $\begin{array}{c}2.00[1.00 \\
5.00]\end{array}$ \\
\hline
\end{tabular}

Social and Economic 


\section{Conservatism Scale ${ }^{c}$}

Mean (SD)

Median [Min, Max]

$$
59.7 \text { (18.4) }
$$

56.5 [24.1, 94.9]

Social Dominance Orientation d

Mean (SD)

Median [Min, Max]

Missing

$2.70(1.53)$

$$
2.50[1.00 \text {, }
$$$$
6.25]
$$

$$
\begin{gathered}
53.0(20.0) \\
53.6[4.17 \\
89.7]
\end{gathered}
$$

2.65 (1.64)

2.63 (1.72)

$2.31[1.00$, 7.00]

$2.13[1.00$, 7.00] 56.7 (19.5)

57.1 (13.6)

59.0 (17.8)

$0(0 \%)$
$54.8[29.4$, 83.3]

61.5 [11.4, $87.5]$

Note: Test-retest reliability was not calculated for the average face ratings as they were only rated once.

a,b Participants self-reported on a scale of 1 (never) to 7 (all the time) how often they are in contact with immigrants in general and with undocumented immigrants specifically on a daily basis.

${ }^{c}$ Participants responded whether they strongly oppose (1) or strongly favor (7) eight items related to preferences for group hierarchies (e.g., "Some groups of people are simply inferior to other groups.") (Ho et al., 2015). Item scores are reverse-corrected and averaged to compute a single score where higher numbers reflect greater dominance orientation.

${ }^{d}$ The Social and Economic Conservatism Scale (SECS) was used to assess political orientation (Everett, 2013). The scale presents 12 political topics (e.g., military, abortion, gun ownership, patriotism). Participants respond on a temperature-like scale (0 (negative) to 100 (positive)) how they feel about each issue. Scores are reverse-corrected and averaged across topics to produce a final score where closer to 0 is more liberal and closer to 100 is more conservative. 
Supplementary Table S2. Participant demographics in Study 1, individual face ratings

\begin{tabular}{|c|c|c|c|c|}
\hline & $\begin{array}{c}\text { Dangerous } \\
(\mathbf{N}=\mathbf{3 7})\end{array}$ & $\begin{array}{c}\text { Competent } \\
(\mathbf{N}=\mathbf{3 0})\end{array}$ & $\begin{array}{l}\text { Trustworthy } \\
(\mathbf{N}=\mathbf{3 3})\end{array}$ & $\underset{(N=35)}{\text { American }}$ \\
\hline \multicolumn{5}{|l|}{ Age } \\
\hline Mean (SD) & $39.1(11.4)$ & $38.4(11.2)$ & $36.7(13.1)$ & $38.3(14.0)$ \\
\hline Median [Min, Max] & $\begin{array}{c}39.0[3.00 \\
\quad 69.0]\end{array}$ & $\begin{array}{c}36.0[19.0 \\
63.0]\end{array}$ & $\begin{array}{c}33.0[22.0, \\
\quad 68.0]\end{array}$ & $\begin{array}{c}32.0[23.0, \\
71.0]\end{array}$ \\
\hline \multicolumn{5}{|l|}{ Gender } \\
\hline Female & $18(48.6 \%)$ & $14(46.7 \%)$ & $10(30.3 \%)$ & $20(57.1 \%)$ \\
\hline Male & $19(51.4 \%)$ & $16(53.3 \%)$ & $22(66.7 \%)$ & $15(42.9 \%)$ \\
\hline Non-binary/Other & $0(0 \%)$ & $0(0 \%)$ & $1(3.0 \%)$ & $0(0 \%)$ \\
\hline \multicolumn{5}{|l|}{ Race } \\
\hline Asian/Pacific Islander & $3(8.1 \%)$ & $0(0 \%)$ & $3(9.1 \%)$ & $3(8.6 \%)$ \\
\hline Black or African & $3(8.1 \%)$ & $2(6.7 \%)$ & $3(9.1 \%)$ & $4(11.4 \%)$ \\
\hline White or European & $31(83.8 \%)$ & $25(83.3 \%)$ & $26(78.8 \%)$ & $25(71.4 \%)$ \\
\hline Multiracial & $0(0 \%)$ & $2(6.7 \%)$ & $1(3.0 \%)$ & $2(5.7 \%)$ \\
\hline Other & $0(0 \%)$ & $1(3.3 \%)$ & $0(0 \%)$ & $0(0 \%)$ \\
\hline Latinx/o/a or Hispanic & $0(0 \%)$ & $0(0 \%)$ & $0(0 \%)$ & $1(2.9 \%)$ \\
\hline \multicolumn{5}{|l|}{ Was born in U.S. } \\
\hline No & $1(2.7 \%)$ & $1(3.3 \%)$ & $1(3.0 \%)$ & $3(8.6 \%)$ \\
\hline Yes & $36(97.3 \%)$ & $29(96.7 \%)$ & $32(97.0 \%)$ & $32(91.4 \%)$ \\
\hline \multicolumn{5}{|l|}{ Is U.S. Citizen } \\
\hline Yes & $37(100 \%)$ & $30(100 \%)$ & $33(100 \%)$ & $33(94.3 \%)$ \\
\hline No & $0(0 \%)$ & $0(0 \%)$ & $0(0 \%)$ & $2(5.7 \%)$ \\
\hline \multicolumn{5}{|l|}{ Lives in US } \\
\hline I am living in the U.S. & $37(100 \%)$ & $30(100 \%)$ & $33(100 \%)$ & $35(100 \%)$ \\
\hline \multicolumn{5}{|l|}{$\begin{array}{l}\text { Immigrant } \\
\text { contact }^{\text {a }}\end{array}$} \\
\hline Mean (SD) & $3.35(1.96)$ & $3.17(1.76)$ & $3.27(1.59)$ & $3.46(2.01)$ \\
\hline Median [Min, Max] & $\begin{array}{c}2.00[1.00, \\
7.00]\end{array}$ & $\begin{array}{l}3.00[1.00 \\
\quad 7.00]\end{array}$ & $\begin{array}{c}3.00[1.00 \\
\quad 6.00]\end{array}$ & $\begin{array}{c}3.00[1.00, \\
7.00]\end{array}$ \\
\hline \multicolumn{5}{|l|}{$\begin{array}{l}\text { Undocumented } \\
\text { contact }^{b}\end{array}$} \\
\hline Mean (SD) & $1.89(1.02)$ & $2.03(1.52)$ & $2.15(1.37)$ & $2.06(1.21)$ \\
\hline Median [Min, Max] & $\begin{array}{c}2.00[1.00, \\
5.00]\end{array}$ & $\begin{array}{c}2.00[1.00 \\
\quad 7.00]\end{array}$ & $\begin{array}{c}2.00[1.00, \\
\quad 5.00]\end{array}$ & $\begin{array}{c}2.00[1.00, \\
6.00]\end{array}$ \\
\hline
\end{tabular}




\begin{tabular}{ccccc}
\hline & $\begin{array}{c}\text { Dangerous } \\
(\mathbf{N}=\mathbf{3 7})\end{array}$ & $\begin{array}{c}\text { Competent } \\
\mathbf{( N = 3 0 )}\end{array}$ & $\begin{array}{c}\text { Trustworthy } \\
\mathbf{( N = 3 3 )}\end{array}$ & $\begin{array}{c}\text { American } \\
\mathbf{( N = 3 5 )}\end{array}$ \\
\hline Mean (SD) & $57.6(18.0)$ & $59.0(22.2)$ & $55.0(21.0)$ & $58.9(19.8)$ \\
Median [Min, Max] & $55.5[22.1$, & $57.3[12.5$, & $50.3[16.8$, & $59.8[18.1$, \\
& $90.1]$ & $97.5]$ & $92.3]$ & $95.8]$ \\
Social Dominance Orientation ${ }^{\mathbf{d}}$ & & & & \\
Mean (SD) & $2.56(1.58)$ & $2.63(1.71)$ & $2.25(1.43)$ & $2.71(1.52)$ \\
Median [Min, Max] & $2.13[1.00$, & $2.25[1.00$, & $1.75[1.00$, & $2.50[1.00$, \\
& $6.63]$ & $6.25]$ & $6.13]$ & $6.13]$ \\
Missing & $2(5.4 \%)$ & $1(3.3 \%)$ & $1(3.0 \%)$ & $1(2.9 \%)$ \\
Test-retest reliability & \multicolumn{3}{c}{} & \\
Mean (SD) & $0.372(0.191)$ & $0.287(0.171)$ & $0.399(0.245)$ & $0.372(0.217)$ \\
& & 0.246 & 0.403 & 0.376 \\
Median [Min, Max] & $0.418[\sim 0$, & {$[0.0474$,} & {$[0.00550$,} & {$[0.0249$,} \\
& $0.724]$ & $0.658]$ & $0.797]$ & $0.803]$ \\
\hline
\end{tabular}

$\overline{a, b, c, d}$ See Supplementary Table S1 for more information on the tagged individual difference measures. 
Supplementary Table S3. Participant demographics in Study 2, similarity sorting task

\begin{tabular}{|c|c|}
\hline & $\begin{array}{c}\text { Overall } \\
(\mathrm{N}=201)\end{array}$ \\
\hline \multicolumn{2}{|l|}{ Age } \\
\hline Mean (SD) & $39.0(11.4)$ \\
\hline Median [Min, Max] & $36.0[20.0,72.0]$ \\
\hline \multicolumn{2}{|l|}{ Gender } \\
\hline Female & $103(51.2 \%)$ \\
\hline Male & $96(47.8 \%)$ \\
\hline Other & $2(1.0 \%)$ \\
\hline \multicolumn{2}{|l|}{ Race } \\
\hline Asian/Pacific Islander & $16(8.0 \%)$ \\
\hline Black or African & $11(5.5 \%)$ \\
\hline Indigenous & $1(0.5 \%)$ \\
\hline Latinx/o/a or Hispanic & $4(2.0 \%)$ \\
\hline Multiracial & $9(4.5 \%)$ \\
\hline Other & $1(0.5 \%)$ \\
\hline White or European & $159(79.1 \%)$ \\
\hline \multicolumn{2}{|l|}{ Was born in U.S. } \\
\hline No & $12(6.0 \%)$ \\
\hline Yes & $189(94.0 \%)$ \\
\hline \multicolumn{2}{|l|}{ Is U.S. citizen } \\
\hline No & $3(1.5 \%)$ \\
\hline Yes & $198(98.5 \%)$ \\
\hline \multicolumn{2}{|l|}{ Lives in U.S. } \\
\hline I am living in the U.S. & $199(99.0 \%)$ \\
\hline I am living outside the U.S. & $2(1.0 \%)$ \\
\hline \multicolumn{2}{|l|}{$\begin{array}{l}\text { Immigrant } \\
\text { contact }^{\text {a }}\end{array}$} \\
\hline Mean (SD) & $3.94(1.93)$ \\
\hline Median [Min, Max] & $4.00[1.00,7.00]$ \\
\hline \multicolumn{2}{|l|}{$\begin{array}{l}\text { Undocumented } \\
\text { contact }^{b}\end{array}$} \\
\hline Mean (SD) & $2.35(1.48)$ \\
\hline Median [Min, Max] & $2.00[1.00,7.00]$ \\
\hline
\end{tabular}




\begin{tabular}{|c|c|}
\hline & $\begin{array}{r}\text { Overall } \\
(\mathrm{N}=201)\end{array}$ \\
\hline Mean (SD) & $57.6(18.9)$ \\
\hline Median [Min, Max] & $56.8[8.75,100]$ \\
\hline \multicolumn{2}{|c|}{ Social Dominance Orientation ${ }^{d}$} \\
\hline Mean (SD) & $2.27(1.26)$ \\
\hline Median [Min, Max] & $1.88[1.00,6.63]$ \\
\hline
\end{tabular}


Supplementary Table S4. Correlations between similarity matrices.

\begin{tabular}{|c|c|c|c|c|c|c|}
\hline \multirow[b]{2}{*}{ Matrix pairs } & \multicolumn{3}{|c|}{ Raw correlations } & \multicolumn{3}{|c|}{ Partial Correlations } \\
\hline & Lower CI & $\rho$ & Upper CI & Lower CI & $\rho$ & Upper CI \\
\hline Visual-American & .48 & .49 & .51 & .31 & .33 & .34 \\
\hline Visual-Dangerous & .25 & .26 & .28 & .03 & .05 & .07 \\
\hline Visual-Trustworthy & .24 & .26 & .27 & .01 & .03 & .05 \\
\hline Visual-Competent & .31 & .33 & .35 & .07 & .09 & .11 \\
\hline Visual-Pixel & .36 & .37 & .39 & .23 & .25 & .26 \\
\hline American-Dangerous & .32 & .33 & .35 & .04 & .06 & .08 \\
\hline American-Trustworthy & .37 & .38 & .40 & .15 & .17 & .18 \\
\hline American-Competent & .45 & .46 & .48 & .25 & .27 & .29 \\
\hline American-Pixel & .31 & .33 & .34 & .12 & .14 & .16 \\
\hline Dangerous-Trustworthy & .51 & .52 & .54 & .41 & .42 & .44 \\
\hline Dangerous-Competent & .33 & .35 & .36 & .10 & .12 & .13 \\
\hline Dangerous-Pixel & .19 & .21 & .23 & .08 & .10 & .11 \\
\hline Trustworthy-Competent & .37 & .39 & .40 & .16 & .17 & .19 \\
\hline Trustworthy-Pixel & .12 & .14 & .15 & -.08 & -.06 &.-.04 \\
\hline Competent-Pixel & .21 & .23 & .24 & .03 & .05 & .07 \\
\hline
\end{tabular}

